\title{
OSTEOGENIC EFFICIENCY OF IN SITU GELLING POLOXAMINE SYSTEMS WITH AND WITHOUT BONE MORPHOGENETIC PROTEIN-2 ${ }^{\S}$
}

Ana Rey-Rico ${ }^{1}$, Maite Silva², José Couceiro², Angel Concheiro ${ }^{1}$ and Carmen Alvarez-Lorenzo ${ }^{1, *}$

\author{
${ }^{1}$ Departamento de Farmacia y Tecnología Farmacéutica, Facultad de Farmacia, \\ ${ }^{2}$ Instituto de Ortopedia y Banco de Tejidos Musculoesqueléticos, Universidad de Santiago de Compostela, \\ 15782-Santiago de Compostela, Spain
}

$\S$ The work described in this paper is the subject of patent application P201000670 filed by the University of Santiago de Compostela.

\begin{abstract}
In situ gelling solutions for minimally invasive local application of bone growth factors are attracting increasing attention as efficient and patient-friendly alternative to bone grafts and solid scaffolds for repairing bone defects. Poloxamines, i.e., X-shaped poly(ethylene oxide)-poly(propylene oxide) block copolymers with an ethylenediamine core (Tetronic ${ }^{\circledR}$ ), were evaluated both as an active osteogenic component and as a vehicle for rhBMP-2 injectable implants. After cytotoxicity screening of various poloxamine varieties, Tetronic 908, 1107, 1301 and 1307 solutions were chosen as the most cytocompatible and their sol-to-gel transitions were rheologically characterized. Viscoelastic gels, formed at $37{ }^{\circ} \mathrm{C}$, sustained protein release under physiological-like conditions. Formulations of rhBMP-2 led to differentiation of mesenchymal stem cells to osteoblasts, quantified as alkaline phosphatase activity with a maximum at day 7 , and to mineralized nodules. Interestingly, poloxamine solely gels led to an initial proliferation of the mesenchymal stem cells (first week), followed by differentiation to osteoblasts (second to third week). Histochemical analysis revealed that Tetronic 908 is only osteoinductive; Tetronic 1107 is mostly osteoinductive, although its use leads to a minor differentiation to adipocytes; Tetronic 1307, solely or loaded with rhBMP-2, causes differentiation of both osteoblasts and adipocytes. Enhanced expression levels of CBFA-1 and collagen type I were observed for Tetronic 908, 1107 and 1307, both solely and combined with rhBMP-2. The intrinsic osteogenic activity of poloxamines (not observed for Pluronic F127) offers novel perspectives for bone regeneration using minimally invasive procedures (i.e., injectable scaffolds) and overcoming the safety and the cost/ effectiveness concerns associated with large scale clinical use of recombinant growth factors.
\end{abstract}

Keywords: BMP-2, poloxamine, osteogenic induction, bone regeneration, scaffold, controlled release, injectable hydrogel, PEO-PPO block copolymers, in situ gelling.

*Address for correspondence:

Carmen Alvarez-Lorenzo

Departamento de Farmacia y Tecnología Farmacéutica, Facultad de Farmacia, Universidad de Santiago de Compostela, 15782-Santiago de Compostela, Spain

Telephone Number: 34981563100 (14876)

FAX Number: 34981547148

E-mail: carmen.alvarez.lorenzo@usc.es
Bone and cartilage regeneration has become a hot research topic in the past decade (Puppi et al., 2010). The high prevalence of degenerative diseases as well as accidental fractures prompted the search of alternatives to the autogenous and allogeneic grafts. Tissue engineering approaches aim to develop scaffolds that can induce and guide cell proliferation, differentiation and new tissue formation at the site of tissue injury or defect. The scaffolds contain cells or biomolecules that can attract cells and growth factors - small molecules or peptides that promote cell survival and tissue regeneration (Kim and Valentini, 2002; Schoichet, 2010). Bone morphogenetic proteins (BMPs) from bone matrix regulate the differentiation and function of the cells involved in bone and cartilage formation, including osteoblasts and chondrocytes (Urist, 1965; Cowan et al., 2005; Reddi, 2005). Most clinical trials have focused on the use of human recombinant BMP-2 (rhBMP-2) since it is one of the most potent inductors of bone formation in vivo (Cheng et al., 2003; Takahashi et al., 2005; Bishop and Einhorn, 2007; Bessa et al., 2008a). In several types of cell cultures, BMP-2 increases the expression of alkaline phosphatase (ALP), osteopontin, osteocalcin, and collagen type I (Jeon et al., 2007). However, BMP-2 administered in solution is quite unstable, rapidly loses its bioactivity and is not retained at the application site long enough for the effective healing of fractures in large animals (Seeherman et al., 2004). The elimination half-life of BMP-2 in nonhuman primates has been found to be about 6-7 min (Poynton and Lane, 2002). Therefore, the design of delivery systems able to protect growth factors from premature degradation, to retain them at the bone injury or defect, and to sustain their release is a clinical requirement (Hsieh et al., 2006; Jeon et al., 2007; Bishop and Einhorn, 2007). An ideal BMP delivery system should be biocompatible, biodegradable or bioeliminable, malleable, easy to handle and sterilizable and should act as a structural template to fill the tissue lesion (Geiger $e t$ al., 2003; Seeherman and Wozney, 2005; Issa et al., 2008).

Most scaffolds are solid matrices based on collagen type I, since it is the most abundant component of the extracellular bone matrix synthesized by osteoblasts (Winn et al., 1999). Collagen sponges loaded with rhBMP-2 and/or rhBMP-7 were given FDA approval in 2002 for use in non-union, open tibial fractures and spinal fusions (McKay et al., 2007; White et al., 2007). The main limitations of collagen matrices are their high degradation rate and their poor capability to prevent free diffusion of the growth factors, resulting in a high 

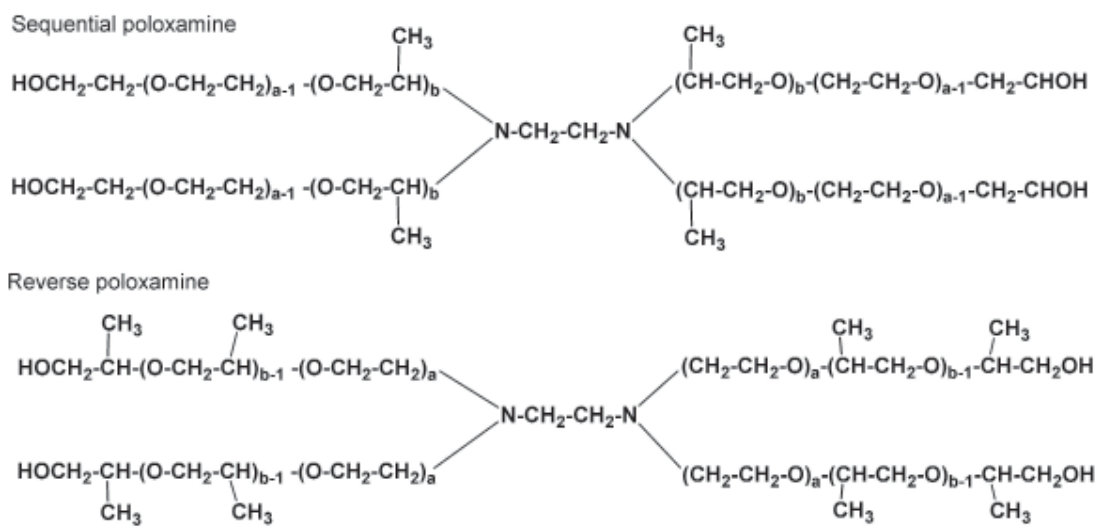

Fig. 1. Structure of sequential and reverse-sequential poloxamines.

initial burst release (Helm et al., 1997; Takahashi et al., 2005). Alternative materials such as gelatin $/ \beta$-tricalcium phosphate (Yang et al., 2005), poly(L-lactic acid) (PLA) (Kim et al., 2008), poly(L-lactic-co-glycolic acid) (PLGA) (Jeon et al., 2007; Shen et al., 2009), hyaluronic acid (Kim and Valentini, 2002), fibrin gel (Itosaka et al., 2009) or porous hydroxyapatite composites (Sopyana et al., 2007) are under study. The recent developments in the research of BMP delivery carriers have been comprehensively revised by Bessa et al. (2008a,b). The use of organic solvents or the high temperature conditions required for preparing hydrophobic matrices (Bessa et al., 2008b) and the deleterious effect of the degradation substances from certain polymers, such as polylactic acid (Puppi et al., 2010), may compromise the stability of the BMPs and the healing of the bone. As an alternative to the preformed implantable scaffolds, injectable bone-filling materials that enable minimally invasive management of the bone defects are gaining increasing attention (Puppi et al., 2010).

Temperature-sensitive block copolymers bearing poly(ethylene oxide), PEO, are endowed with features that mimic those of the extracellular matrix whilst enabling the formulation of aqueous systems that are easily syringeable at room temperature and lead to highly viscoelastic gels at $37^{\circ} \mathrm{C}$ (Lutolf et al., 2003a,b; Pratt et al., 2004; He et al., 2008; Yu and Ding, 2008). The low surface tension of the gels enables the loading of proteins in the aqueous phase of the hydrogel without denaturing, while the sol-to-gel transition makes the sustained release under physiological conditions possible (Bromberg and Ron, 1998; Kabanov and Alakhov, 2002). Although still few, the studies carried out with polypropylene fumarate-PEG (Fisher et al., 2004) and poly(ethylene oxide)-poly(propylene oxide)-poly(ethylene oxide), PEO-PPO-PEO, poloxamer (Pluronic ${ }^{\circledR}$ ) triblock copolymers (Issa et al., 2008) evidenced the ability of in situ gelling systems to regulate the delivery of BMP-2 and BMP-7. Comparatively to biodegradable polymers, such as PLA or PLGA, which are not completely reabsorbed and radiographically appear as voids or black holes in the formed bone, poloxamer can be completely replaced by the new bone (Clokie and Urist, 2000). Once in blood, poloxamers are rapidly excreted in the urine, with minor accumulation in lung, liver, brain, and kidney tissue, and no risk of reproductive and/or developmental toxicity has been reported (Cosmetic Ingredient Review (CIR) Expert Panel, 2008).
Small synthesizable organic molecules, such as simvastatin (Jeong and Puleo, 2009) and polyamines, appear as an advantageous alternative to the use of the expensive recombinant growth factors. Natural polyamines, such as spermidine, spermine and their precursors ornitine and putrescine, have been recently claimed to induce the differentiation of mesenchymal stem cells into osteoblasts (Helder and Wuisman, 2007; Tjabringa et al., 2008), although their mechanisms of action are still not completely elucidated and the way of delivery is not established yet. The search for combining the osteoinductive capability of amine-bearing synthetic molecules with an affordable administration by minimally invasive techniques prompted us to explore the potential of block copolymers of the family of poloxamines. Poloxamines, commercially available under the trade name of Tetronic ${ }^{\circledR}$, are X-shaped copolymers that bear four PEO-PPO arms connected to a central ethylenediamine group (Fig. 1). Differently from the natural polyamines that bear amine groups at one or both ends and the distance between amine groups inside the chain is of 3 or more carbon atoms, poloxamines only have two amine groups, which are separated by 2 carbon atoms and never placed at the end of the copolymer chain. The poloxamines has been exploited until now for rendering dually temperature and $\mathrm{pH}$ responsive micelles and gels (Alvarez-Lorenzo et al., 2007, 2010a,b; Gonzalez-Lopez et al., 2008, 2010; Chiappetta et al., 2010), to favor the interactions with cells of tissue engineered-modular construct (Chiappetta and Sosnik, 2007) and to inhibit P-glycoprotein efflux (Alvarez-Lorenzo et al., 2010a). The aim of this work was to elucidate the potential of poloxamines as the sole component of injectable scaffolds able to induce bone formation, but also as suitable carriers of rhBMP-2. The present study was organized in three main steps: (i) first, a cytocompatibility screening of poloxamine varieties covering a wide range of structural features (namely, molecular weight, length of the PEO and PPO blocks, and spatial arrangement of the blocks; Table 1) was carried out in order to identify the copolymers more suited to be in contact with mesenchymal stem cells and osteoblasts; (ii) second, the temperature-induced gelling, the incidence of autoclave sterilization on the viscoelastic properties of poloxamine solutions and their capability to control the delivery of a model protein (bovine serum albumin, BSA) were investigated; and (iii) finally, in vitro release 
Table 1. Average molecular weight (BASF web page) and structural features of sequential $\left(\left(\mathrm{OE}_{\mathrm{a} / 4} \mathrm{OP}_{\mathrm{b} / 4}\right)_{2} \mathrm{NCH}_{2} \mathrm{C}\right.$ $\left.\mathrm{H}_{2} \mathrm{~N}\left(\mathrm{OP}_{\mathrm{b} / 4} \mathrm{OE}_{\mathrm{a} / 4}\right)_{2}\right)$ and reverse $\left(\left(\mathrm{OP}_{\mathrm{b} / 4} \mathrm{OE}_{\mathrm{a} / 4}\right)_{2} \mathrm{NCH}_{2} \mathrm{CH}_{2} \mathrm{~N}\left(\mathrm{OE}_{\mathrm{a} / 4} \mathrm{OP}_{\mathrm{b} / 4}\right)_{2}\right)$ poloxamine varieties, Tetronic ${ }^{\circledR}$ (Chiappetta and Sosnik, 2007), and of the poloxamer variety, Pluronic ${ }^{\circledR} \mathrm{F} 127\left(\mathrm{OE}_{\mathrm{a} / 2}-\mathrm{OP}_{\mathrm{b}}-\mathrm{OE}_{\mathrm{a} / 2}\right)$ used as a control (Kabanov and Alakhov, 2002).

\begin{tabular}{|l|c|c|c|}
\hline \multicolumn{1}{|c|}{ Copolymer } & Molecular weight (Da) & Total EO units (a) & Total PO units (b) \\
\hline Tetronic $^{\circledR} 304$ & 1650 & 15.0 & 17.1 \\
Tetronic $^{\circledR} 901$ & 4700 & 10.7 & 72.9 \\
Tetronic $^{\circledR} 904$ & 6700 & 60.9 & 69.3 \\
Tetronic $^{\circledR} 908$ & 25000 & 454.5 & 86.2 \\
Tetronic $^{\circledR} 1107$ & 15000 & 238.6 & 77.6 \\
Tetronic $^{\circledR} 1301$ & 6800 & 15.5 & 105.5 \\
Tetronic $^{\circledR} 1307$ & 18000 & 286.4 & 93.1 \\
Tetronic $^{\circledR} 150 \mathrm{R} 1$ & 7900 & 20 & 116.0 \\
Pluronic $^{\circledR}$ F127 & 12600 & 200 & 69 \\
\hline
\end{tabular}

of rhBMP-2 and bioactivity and gene expression assays (cell differentiation to osteoblasts) were simultaneously carried out. Pluronic F127 was also included in the study as a control since this FDA-approved linear copolymer possesses certain structural similarities with poloxamines (namely, PEO and PPO blocks) and has been previously shown suitable as BMP-2 vehicle (Issa et al., 2008). Selective staining to reveal differentiation to other lineages, namely adipocytes or chondrocytes, was also applied. The overall analysis of the information obtained may enable the relating of structural features of poloxamines with their osteoinductive ability and performance as BMP-2 carriers and should contribute to the rational design of optimized injectable scaffolds for tissue engineering.

\section{Materials and Methods}

\section{Materials}

Poloxamines Tetronic ${ }^{\circledR}$ 304, 901, 904, 908, 1107, 1301, 1307 and 150R1 (Table 1) and poloxamer Pluronic ${ }^{\circledR}$ F127 were supplied by BASF (Ludwigshafen, Germany); bovine serum albumin (BSA) and sodium azide by Fluka (now Sigma-Aldrich, St. Louis, MO, USA); rhBMP-2 (InductOs $^{\text {TM }} 12 \mathrm{mg}, 1.5 \mathrm{mg} / \mathrm{ml}$ ) by Wyeth Farma S.A. (now Pfizer, New York, NY, USA); kit ELISA Quantikine Immunoassay BMP-2 by R\&D Systems (Minneapolis, MN, USA); alkaline phosphatase (ALP) substrate and p-nitrophenylphosphate solution by Sigma-Aldrich; kit BCA by Pierce (Rockford, IL, USA); and Cytotoxicity Detection $\mathrm{Kit}^{\mathrm{PLUS}}$ (lactate dehydrogenase, LDH) by Roche (Basel, Switzerland). Balb/3T3 mouse fibroblasts clone A31 (CCL-163), CHO-K1 epithelial cells from ovary of chinese hamster (CCL-61) and SAOS-2 human osteogenic sarcoma cells (HTB-85) were purchased from the American Type Culture Collection (LGC Standards, Manassas VA). Mesenchymal stem cells StemPRO ${ }^{\circledR}$ human adipose-derived stem cells were supplied by Gibco (Invitrogen, Carlsbad, CA, USA). Dulbecco's Modified Eagle medium (D-MEM) Nutrient mixture F-12 Ham without phenol red was supplied by Sigma-Aldrich (USA) and MesenPRO RS ${ }^{\mathrm{TM}}$ medium (MesenPRO RS ${ }^{\mathrm{TM}}$ Basal Medium and MesenPRO RS TM Growth Supplement) by Gibco (Invitrogen). Fetal bovine serum (FBS) was supplied by BioWhittaker ${ }^{\circledR}$ Lonza (Basel, Switzerland), gentamicine from B. Braun (Melsungen, Germany), $\beta$-glycerophosphate, dexamethasone and ascorbic acid by Sigma-Aldrich. Purified water was obtained by reverse osmosis (MilliQ ${ }^{\circledR}$, Millipore, now Merck, Darmstadt, Germany). Other reagents were of analytical grade.

\section{Cytocompatibility screening}

Tetronic 304, 901, 904, 908, 1107, 1301, 1307 and 150R1 solutions $(10 \% \mathrm{w} / \mathrm{w})$ were prepared by dissolving the required amount of each polymer in phosphate buffer $\mathrm{pH}$ 7.4. The solutions were filtered by $0.2 \mu \mathrm{m}$ membranes (Millex $^{\mathrm{TM}}$, Millipore). Balb/3T3 and CHO-K1 cells were cultured in D-MEM /Nutrient mixture F-12 Ham without phenol red, containing $10 \% \mathrm{v} / \mathrm{v}$ FBS and gentamicine ( $0.1 \mathrm{mg} / \mathrm{mL}) .5,000$ cells/well $(50 \mu \mathrm{L}$ medium $)$ were seeded in 96-well plates and $50 \mu \mathrm{L}$ of polymer solutions (conveniently diluted to $0.01,0.1,1$ and $5 \%$ ) were added. Final FBS concentration was $5 \% \mathrm{v} / \mathrm{v}$. Negative and positive controls were carried out by replacing the polymer solutions with D-MEM solely or D-MEM containing a lysis factor (included in the Cytotoxicity Detection $\mathrm{Kit}^{\mathrm{PLUS}}$ (LDH), Roche), respectively. Plates were incubated for one or three days at $37{ }^{\circ} \mathrm{C}$, in a $5 \% \mathrm{CO}_{2}$ humidified atmosphere. Cells survival was evaluated at 24 and $72 \mathrm{~h}$ by using the Cytotoxicity Detection $\mathrm{Kit}^{\mathrm{PLUS}}$ (LDH) and the absorbance was measured at $490 \mathrm{~nm}$ using a microplate reader (BIORAD Model 680, Hercules, CA USA). Each experiment was carried out in triplicate and repeated twice.

\section{Osteoblast viability}

Tetronic 908, 1107, 1301 and 1307 solutions at 20\% w/w were prepared in D-MEM without phenol red and filtered through $0.2 \mu \mathrm{m}$ membranes (Millex ${ }^{\mathrm{TM}}$, Millipore). SAOS-2 cells were cultured in D-MEM supplemented with $10 \% \mathrm{w} / \mathrm{v}$ FBS and gentamicine ( $0.1 \mathrm{mg} / \mathrm{mL})$. 200,000 cells/well (1.5 $\mathrm{mL}$ ) were seeded in 24-well plate (area available for cell growth $1.9 \mathrm{~cm}^{2}$ ) and $0.5 \mathrm{~mL}$ polymer solution was added. Final FBS concentration was $7.5 \% \mathrm{v} / \mathrm{v}$. Some plates were incubated at $37^{\circ} \mathrm{C}$ for $24 \mathrm{~h}$ and others for $72 \mathrm{~h}$. Then, the cells were detached by addition of trypsin and incubated at $37{ }^{\circ} \mathrm{C}$ for $5 \mathrm{~min}$ in a humidified atmosphere with $5 \%$ $\mathrm{CO}_{2}$. After incubation, cells were centrifuged at 1,400 rpm for $4 \mathrm{~min}$ (Eppendorf centrifuge 415R, Eppendorf Ibérica, Madrid, Spain) and resuspended in fresh D-MEM. Aliquots $(100 \mu \mathrm{L})$ of cell suspension diluted with phosphate buffer 
pH $7.4(200 \mu \mathrm{L})$ were transferred to a cytospin (Hettich Zentrifugen, Tuttlingen, Germany; Zytokammer 4x1 mL) and centrifuged in order to fix cells on a microscope slide. Finally, a calcein/propidium iodide staining (phosphate buffer solution: calcein: propidium iodide 98:1:1) was done to assess live/dead populations. Viability values were calculated using a light microscope (Optiphot2, Nikon, Tokyo, Japan) with green and red filters connected to image analysis software (Soft Imaging System $\mathrm{GmbH}$, Münster, Germany; Version 3.2 Build 607, Germany). Each experiment was carried out in triplicate and repeated twice. Cell fraction cultured with Tetronic 1301 could not be harvested, mainly because the hydrophobicity of this copolymer caused it to remain partially adhered to the cells pellet, affecting the cell viability quantification. To overcome this drawback, $1.5 \mathrm{~mL}$ of Tetronic 1301 dispersion were placed into the upper compartment of 6-well plate Transwell ${ }^{\circledR}$ permeable supports and 800,000 cells/well $(2.5 \mathrm{~mL})$ were seeded in the lower compartment (area available for cell growth $9.5 \mathrm{~cm}^{2}$ ). Plates were incubated for $24 \mathrm{~h}$ at $37{ }^{\circ} \mathrm{C}$ in a $5 \% \mathrm{CO}_{2}$ humidified atmosphere and cell viability was determined as explained above. In any of the two osteoblast viability experiments described in this section, the number of SAOS-2 cells was chosen to be close to 100,000 cells per square centimeter of well, as recommended by the manufacturer of the plates.

\section{Oscillatory rheology of poloxamine solutions}

The storage or elastic $\left(\mathrm{G}^{\prime}\right)$ and the loss or viscous $\left(\mathrm{G}^{\prime \prime}\right)$ moduli of 20\% w/w Tetronic 908, 1107, 1301 and 1307 solutions in phosphate buffer $\mathrm{pH} 7.4$ and D-MEM were evaluated in triplicate, before and after being autoclaved (121 ${ }^{\circ} \mathrm{C}, 20 \mathrm{~min}$, Raypa AES-12, Barcelona, Spain), using a Rheolyst AR-1000N rheometer equipped with an AR2500 data analyzer, a Peltier plate and a cone geometry $(6 \mathrm{~cm}$ diameter, $2.1^{\circ}$ ) (TA Instruments, Newcastle, UK). To determine the influence of temperature on both moduli, tests were carried out at $5 \mathrm{rad} / \mathrm{s}$ from $15^{\circ} \mathrm{C}$ to $45^{\circ} \mathrm{C}$ with a heating rate of $2^{\circ} \mathrm{C} / \mathrm{min}$. Evaporation was prevented using silicon oil as solvent trap.

\section{BSA release test}

BSA (50 mg) was added to $20 \% \mathrm{w} / \mathrm{w}$ Tetronic 908,1107 , 1301 and 1307 solutions in phosphate buffer $\mathrm{pH} 7.4$ (8 $\mathrm{mL}) .2 \mathrm{~mL}$ aliquots of each dispersion were placed into test tubes $\left(13.5 \mathrm{~mm}\right.$ inner diameter) at $37{ }^{\circ} \mathrm{C}$. Then, $5 \mathrm{~mL}$ of phosphate buffer $\mathrm{pH} 7.4$ at $37{ }^{\circ} \mathrm{C}$ were slowly added on the gel phase. The system was kept at $37{ }^{\circ} \mathrm{C}$, under oscillating agitation ( $50 \mathrm{osc} / \mathrm{min}$ ), for several weeks. The surface area of the gel in contact with the release medium was $143.1 \mathrm{~mm}^{2}$. Samples of the supernatant $(1 \mathrm{~mL})$ were taken at pre-established time intervals and replaced with equal volume of buffer at $37^{\circ} \mathrm{C}$. BSA concentration was spectrophotometrically determined at $278 \mathrm{~nm}$ (Agilent 5348, Santa Clara, CA, USA). The experiments were carried out in triplicate.

\section{rhBMP-2 release test}

Tetronic 908, 1107 and 1307 and Pluronic F127 at 26.5\% w/w solutions in phosphate buffer $\mathrm{pH} 7.4$ were autoclaved $\left(121^{\circ} \mathrm{C}, 20 \mathrm{~min}\right.$, Raypa AES-12, Barcelona, Spain) and then mixed with rhBMP-2 solution $(0.15 \mathrm{mg} / \mathrm{mL})$. Final copolymer and rhBMP-2 concentrations were $20 \%$ and $0.037 \mathrm{mg} / \mathrm{mL}$, respectively. $1 \mathrm{~mL}$ aliquots of each dispersion were placed into test tubes $(13.5 \mathrm{~mm}$ inner diameter) at $37{ }^{\circ} \mathrm{C}$. Negative controls (copolymer without rhBMP-2) were also tested. Then, $5 \mathrm{~mL}$ of phosphate buffer $\mathrm{pH} 7.4$ with $0.02 \% \mathrm{w} / \mathrm{v}$ sodium azide at $37{ }^{\circ} \mathrm{C}$ were slowly added on the gel phase. The system was kept at 37 ${ }^{\circ} \mathrm{C}$ under oscillating agitation (50 osc/min). The surface area of the gel in contact with the release medium was $143.1 \mathrm{~mm}^{2}$. Samples of the supernatant $(1 \mathrm{~mL})$ were taken at pre-established time intervals, divided into two aliquots $(0.5 \mathrm{~mL})$ and frozen at $-20^{\circ} \mathrm{C}$. Each extracted sample was immediately replaced by $1 \mathrm{~mL}$ buffer at $37^{\circ} \mathrm{C}$. rhBMP-2 concentration in the release medium was quantified after 1:50,000 dilution, using a sandwich enzyme immunoassay technique (Kit ELISA Quantikine Immunoassay BMP2, R\&D Systems). The absorbance at $450 \mathrm{~nm}$, with the correction wavelength set at $540 \mathrm{~nm}$ or $570 \mathrm{~nm}$, was measured using an ELISA reader (BIORAD Model 680 Microplate Reader). Quantification interval ranged from $62.5 \mathrm{pg} / \mathrm{mL}$ to $4,000 \mathrm{pg} / \mathrm{mL}$. Each experiment was carried out in duplicate and repeated twice.

\section{Bioactivity of poloxamine gel formulations: ALP assay and histochemical analyses}

Mesenchymal stem cells were cultured in MesenPRO $\mathrm{RS}^{\mathrm{TM}}$ medium (Gibco, Invitrogen) supplemented with $1 \%$ glutamine and $1 \%$ antimicrobial agents (penicillin, streptomycin, and amphotericin B) and seeded ( $3 \times 10^{4}$ cells/well, $2.5 \mathrm{~mL}$ ) in 6-well plates. $200 \mu \mathrm{L}$ of copolymer dispersion $(20 \% \mathrm{w} / \mathrm{w})$ containing or not rhBMP-2 (0.037 $\mathrm{mg} / \mathrm{ml}$ ) were placed into the upper compartment of 6-well plate Transwell ${ }^{\circledR}$ permeable supports. Thus, the amounts of copolymer (poloxamine or poloxamer) and rhBMP-2 added to each well were $40 \mathrm{mg}$ and $7.4 \mu \mathrm{g}$, respectively. Negative and positive controls were carried out with cells in culture medium (neither copolymer nor rhBMP-2 added) and cells in osteogenic differentiation medium $(10 \mathrm{mM}$ $\beta$-glycerophosphate, $100 \mathrm{nM}$ dexametasone and $50 \mu \mathrm{M}$ ascorbic acid in the culture medium), respectively. Plates were incubated at $37^{\circ} \mathrm{C}$, in a humidified atmosphere with $5 \% \mathrm{CO}_{2}$. The medium was replaced twice a week. Cells were observed at inverted microscopy (10x) to discard possible contamination by bacteria. Each experiment was carried out in triplicate and repeated twice.

To carry out the alkaline phosphatase (ALP) assay, cells were lysed at 3, 7, 14 and $23 \mathrm{~d}$ by addition of 150 $\mu \mathrm{L}$ Tris $\mathrm{HCl}$ buffer $10 \mathrm{mM}$ pH 7.5 with $0.1 \%$ Triton $\mathrm{X}-100$. Samples were exposed to 3 freezing $\left(-80^{\circ} \mathrm{C}\right) /$ thawing cycles (45 min per cycle). Lysates were cleared by centrifugation at $14,000 \mathrm{rpm}$ for $15 \mathrm{~min}$ at $4{ }^{\circ} \mathrm{C}$. The samples $(50 \mu \mathrm{L})$ were incubated with ALP substrate $(150$ $\mu \mathrm{L})$ in 96 -well plates at $37^{\circ} \mathrm{C}$ for $30 \mathrm{~min}$. The absorbance was read at $405 \mathrm{~nm}$ using an ELISA plate reader (BIORAD Model 680 Microplate Reader). A p-nitrophenylphosphate calibration curve was used to determine ALP concentration. Each ALP activity measurement was normalized by the protein content, which was measured by the BCA protein assay (Kim and Valentini, 2002). Results were reported as nanomoles $\mathrm{ALP} / \mathrm{min} / \mathrm{mg}$ protein. 
Various histochemical analyses were carried out in triplicate. ALP activity was visualized at $14 \mathrm{~d}$ as follows. The cells were fixed using 4\% paraformaldehyde solution for $5 \mathrm{~min}$, washed with phosphate buffer, incubated in darkness with $0.1 \%$ naphthol ASMX-phosphate and $0.1 \%$ fast violet in $56 \mathrm{mM}$ AMPD (2-amino-2-methyl propanediol) and observed by light microscopy. Alizarin red staining was used to detect the mineralization of the matrix at 14 and $23 \mathrm{~d}$. Cells were fixed with cold ethanol:water 70:30 v/v for $1 \mathrm{~h}$, washed with water twice, stained with $2 \%$ alizarin red for $30 \mathrm{~min}$, washed with water three times and observed by microscopy. Oil Red O staining was performed at 7, 14 and $23 \mathrm{~d}$, as described by the manufacturer (SC Protocol 00011, Thermo Scientific, Logan, UT, USA), to detect adipogenic activity and mature adipocytes. Chondrogenic differentiation of mesenchymal stem cells was observed using Alcian blue staining. Briefly, after 7,14 and $23 \mathrm{~d}$ in contact with the copolymer gels, the medium was removed and the cells were rinsed once with PBS and fixed with 4\% formaldehyde solution for 30 min. Then, the wells were rinsed with PBS and 1\% Alcian blue solution in $0.1 \mathrm{~N} \mathrm{HCl}$ was added and kept for $30 \mathrm{~min}$. The wells were again rinsed three times with $0.1 \mathrm{~N} \mathrm{HCl}$ and then with water, and the cells were visualized by light microscopy to search for the blue staining indicative of the synthesis of proteoglycans by chondrocytes.

\section{Cell proliferation}

Mesenchymal stem cells were cultured as described above in the presence of copolymer dispersions $(20 \% \mathrm{w} / \mathrm{w})$ containing or not containing rhBMP-2 $(0.037 \mathrm{mg} / \mathrm{mL})$. Cell proliferation was assessed by MTT assay (Roche). At 4, 7, 14 and $23 \mathrm{~d}$ of culture, Transwell ${ }^{\circledR}$ compartments were retired and $1.5 \mathrm{~mL}$ of culture medium withdrawn. Then, $100 \mu \mathrm{L}$ MTT solution ( $5 \mathrm{mg} / \mathrm{mL}$ stock in PBS) were added to each well containing $1 \mathrm{~mL}$ of remaining culture medium and the plates were incubated during $4 \mathrm{~h}$ at $37^{\circ} \mathrm{C}$. Then $1 \mathrm{~mL}$ MTT solvent $(10 \%$ SDS in $0.01 \mathrm{M} \mathrm{HCl})$ was added and incubated overnight at $37^{\circ} \mathrm{C}$. Aliquots of wells were removed, kept in Eppendorf tubes and frozen at -80 ${ }^{\circ} \mathrm{C}$ until analysis. Tubes were centrifuged at $13,000 \mathrm{rpm}$ for $5 \mathrm{~min}$, the supernatants were transferred to 96-well plates and the absorbance was recorded using an ELISA plate reader at $550 \mathrm{~nm}$ (BIORAD Model 680 Microplate Reader, USA). Cell number was estimated from a calibration curve constructed using cultures with known number of cells.

\section{Reverse transcription-polymerase chain reaction (RT-PCR) analysis}

Mesenchymal stem cells were cultured as described in the Bioactivity of poloxamine gel formulations section and total cellular RNA was extracted at days 7, 10 and 14 using TRIzol ${ }^{\circledR}$ (Invitrogen) according to the manufacturer's protocol. Phase separation was carried out using chloroform and the resultant RNA pellets were washed with ethanol:water 70:30 v/v, dried under air and resuspended in DEPC-treated water. The absorbance of RNA systems was measured at $260 \mathrm{~nm}$ using a biophotometer (Eppendorf, Hamburg, Germany) and RNA concentration was calculated. RNA $(5 \mu \mathrm{g})$ was reversed transcribed into cDNA using Maloney murine leukemia virus (M-MLV) reverse transcriptase and random hexamers (Invitrogen). Reverse transcription (RT) conditions were $37^{\circ} \mathrm{C}$ for $50 \mathrm{~min}, 42{ }^{\circ} \mathrm{C}$ for $15 \mathrm{~min}$ and $95{ }^{\circ} \mathrm{C}$ for $5 \mathrm{~min}$. To assess mRNA expression, a semiquantitative RT-PCR method was used by measuring PCR products during the exponential phase of cDNA amplification. The generated cDNA was amplified by using primers for CBFA-1, ALP, and collagen type I (Li et al., 2009). Glyceraldehide-3phosphate dehydrogenase (GAPDH) was used as a control for assessing PCR efficiency (Li et al., 2009). The PCR products were size fractionated onto a $2 \%$ agarose gel and stained with ethidium bromide. Primers sets and PCR products sizes are listed in Table 2.

\section{Statistical analysis}

ALP activity registered for the different copolymers and formulations was compared using ANOVA and the Fisher's Least Significant Differences (LSD) multiple range test (Statgraphics Plus for Windows 5.1, Statistical Graphics Corp., Warrenton, VA, USA).

\section{Results}

\section{Cytocompatibility screening}

A preliminary screening of poloxamine varieties regarding their cytocompatibility against Balb/3T3 fibroblasts and CHO-K1 epithelial-like cells was carried out according to the UNE-EN ISO 10993-5 protocol, although the assay time was not limited to $24 \mathrm{~h}$ but also extended to $72 \mathrm{~h}$. Tetronic 908, 1107, 1301, 1307 and 150R1 were found to be the most cytocompatible poloxamines, showing high

Table 2. Primers sets and PCR products sizes.

\begin{tabular}{|c|c|c|c|}
\hline Gene names & Primers sequences & $\begin{array}{c}\text { Product } \\
\text { size }\end{array}$ & $\begin{array}{c}\text { Annealing } \\
\text { temperature }\end{array}$ \\
\hline $\begin{array}{c}\text { CBFA-1 } \\
\text { (Runx2) }\end{array}$ & $\begin{array}{c}\text { F: 5'CAGACCAGCAGCACTCCATA-3' } \\
\text { R :5'-TCCAATATGGTCGCCAAACA-3' }\end{array}$ & 256 & 52 \\
\hline ALP & $\begin{array}{c}\text { F: 5'-CCCAAAGGCTTCTTCTTG-3' } \\
\text { R: 5-CTGGTAGTTGTTGTGAGCAT-3' }\end{array}$ & 356 & 55 \\
\hline Collagen type I & $\begin{array}{c}\text { F: 5'-CGCCATCAAGGTCTACTGC-3' } \\
\text { R: 5'-GAATCCATCGGTCATGCTCT-3' }\end{array}$ & 148 & 54 \\
\hline GAPDH & $\begin{array}{l}\text { F: 5'-ACCACAGTCCATGCCATCAC-3' } \\
\text { R: 5'-TCCACCACCCTGTTGCTGTA-3' }\end{array}$ & 452 & 55 \\
\hline
\end{tabular}



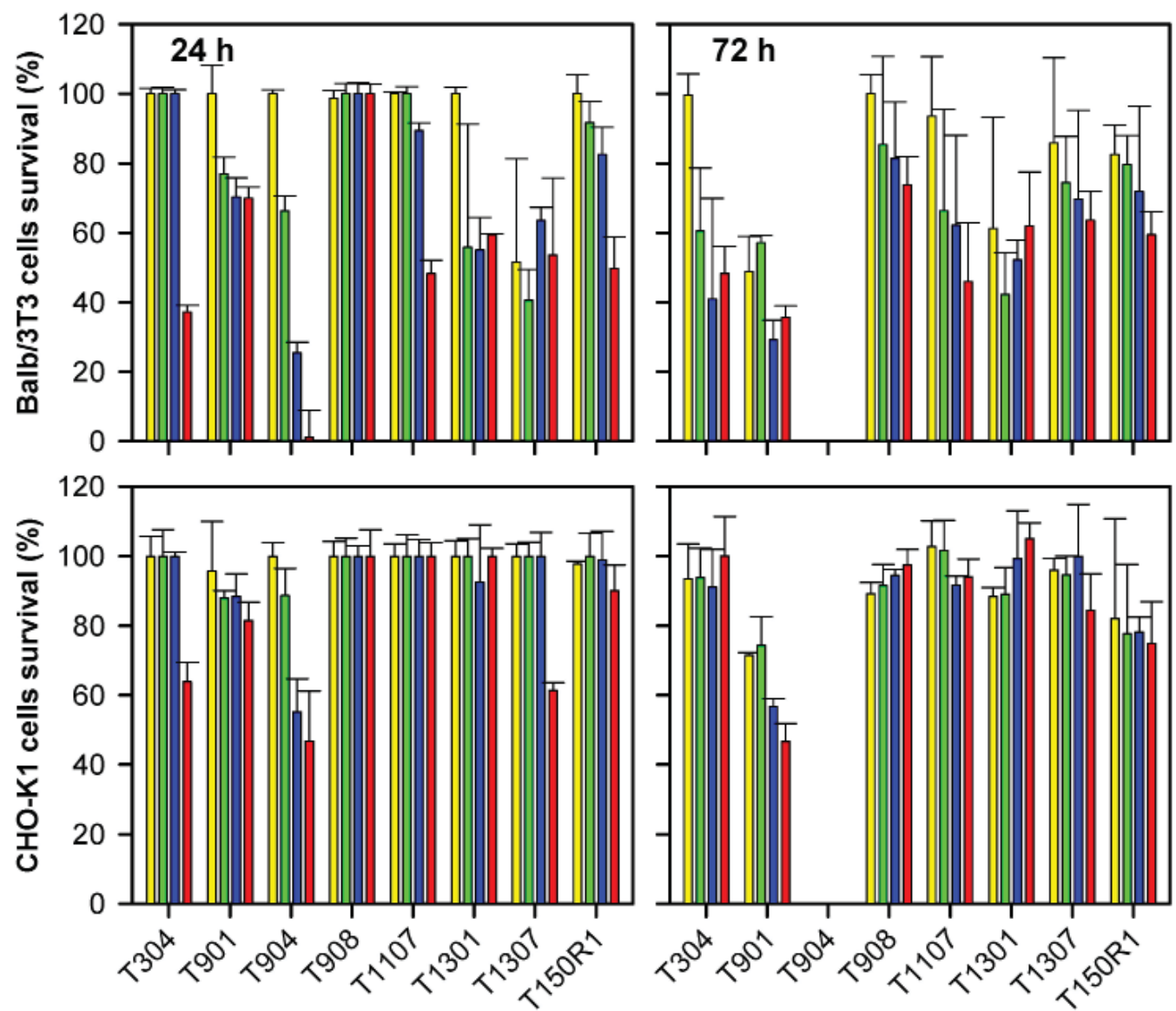

Fig. 2. Cell viability after 24 and $72 \mathrm{~h}$ in contact with poloxamines at $0.01 \% \mathrm{w} / \mathrm{w}$ (yellow columns), $0.1 \% \mathrm{w} / \mathrm{w}$ (green columns), 1\% w/w (blue columns) and 5\% w/w (red columns). All tests were done in triplicate and the standard deviations are shown as error bars.
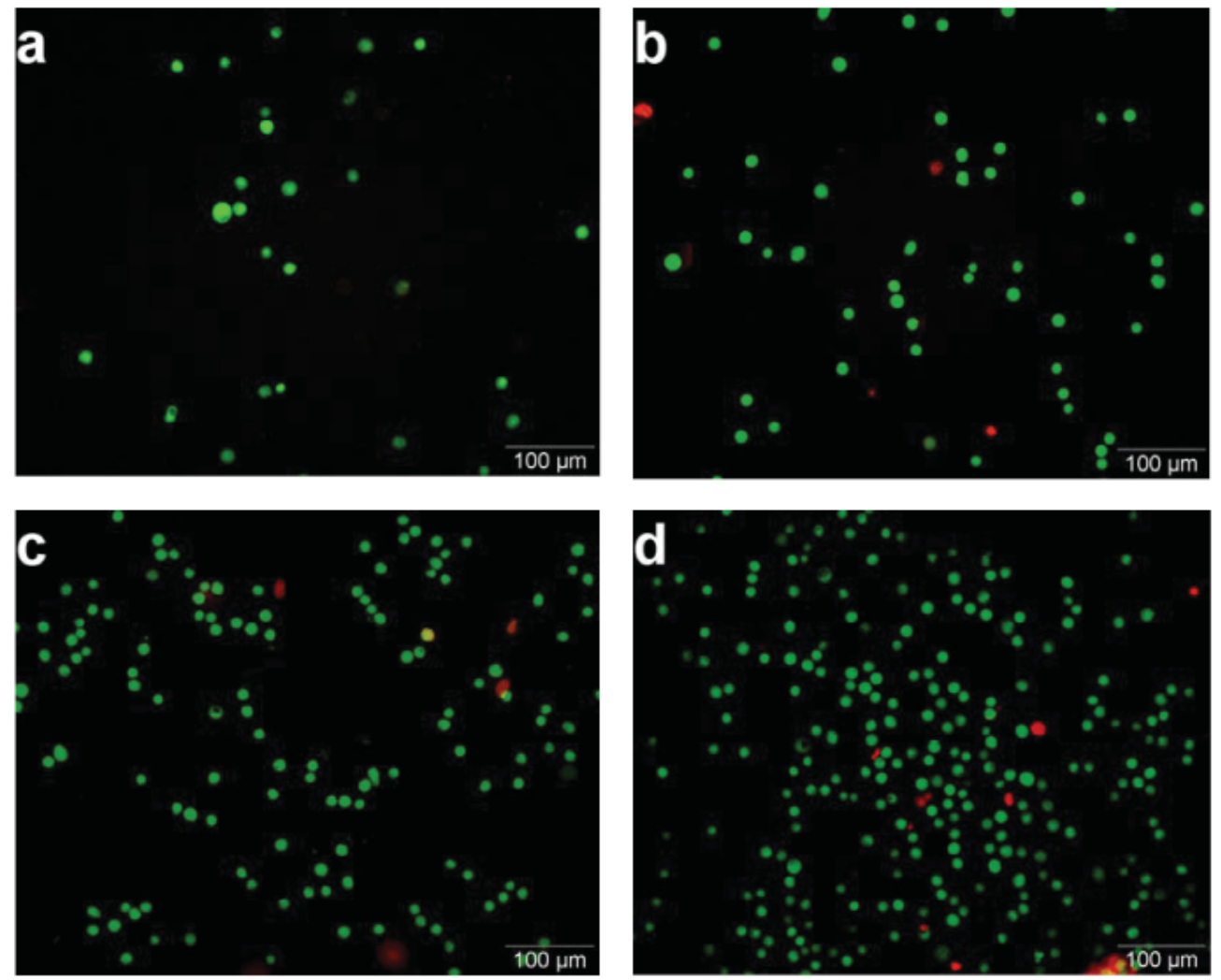

Fig. 3. Viability of SAOS-2 cells after $24 \mathrm{~h}$ in contact with $20 \% \mathrm{w} / \mathrm{w}$ Tetronic 908 (a; $96.7 \%$ viability), Tetronic 1107 (b; $90.3 \%$ ), Tetronic 1301 (c, $95.3 \%$ ) and Tetronic 1307 (d; $95.8 \%$ ). The live cells stained with calcein AM appear in green and the dead cells stained with propidium iodide appear in red. 

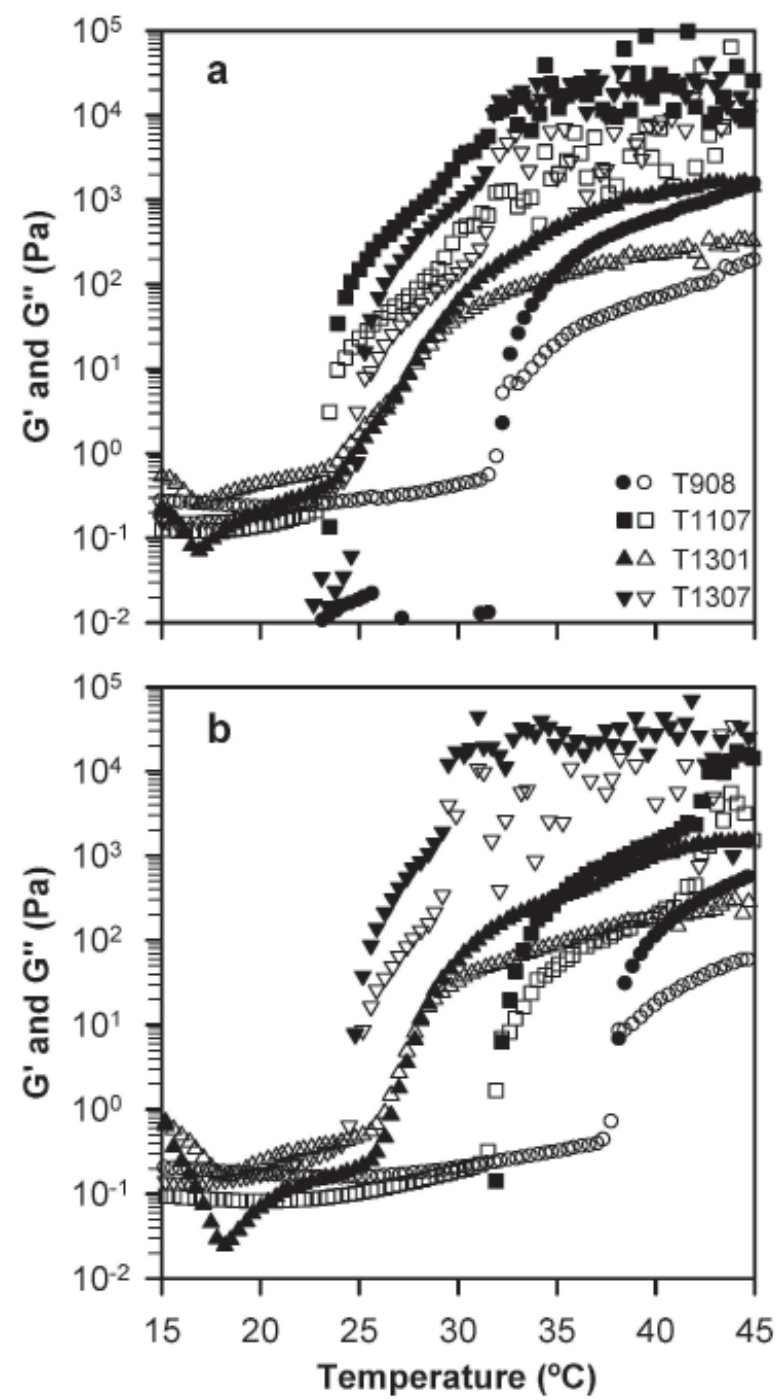

Fig. 4. Temperature dependence of the storage $\left(G^{\prime}\right.$, solid symbols) and loss (G", open symbols) moduli of $20 \% \mathrm{w} / \mathrm{w}$ poloxamine solutions in (a) phosphate buffer $\mathrm{pH} 7.4$ and (b) DMEM after being autoclaved.

viability levels after 24 or $72 \mathrm{~h}$ in contact with the cells (Fig. 2). Correspondingly, Tetronic 901 and 904 were the less cytocompatible, particularly when tested against Balb/3T3 cells. No cell survival was observed after being in contact with Tetronic 904 for $72 \mathrm{~h}$. Cytotoxicity experiments carried with Pluronic F127 revealed $100 \%$ cell survival at $24 \mathrm{~h}$. Balb/3T3 fibroblasts viability at $72 \mathrm{~h}$ was $100 \%$ for $0.01 \%$ Pluronic, but decreased up to $55 \%$ for $5 \%$ Pluronic. CHO-K1 cells viability at $72 \mathrm{~h}$ ranged from 68 to $46 \%$ as the Pluronic F127 concentration increased from 0.01 to $5 \%$.

The viability of SAOS-2 cells (human osteoblast cell line) after $24 \mathrm{~h}$ in the presence of $20 \% \mathrm{w} / \mathrm{w}$ Tetronic 908 , 1107, 1301 and 1307 medium was above $90 \%$ as observed applying the live/dead staining (Fig. 3). It should be noticed that, since Tetronic 1301 is quite hydrophobic, the copolymer remained attached to the cell pellet and an alternative approach had to be implemented to evaluate cytocompatibility. Such an approach consisted in pouring the copolymer solution on the Transwell membrane above the cells inside the well. The number of cells per unit of surface was kept constant in all experiments with SAOS-
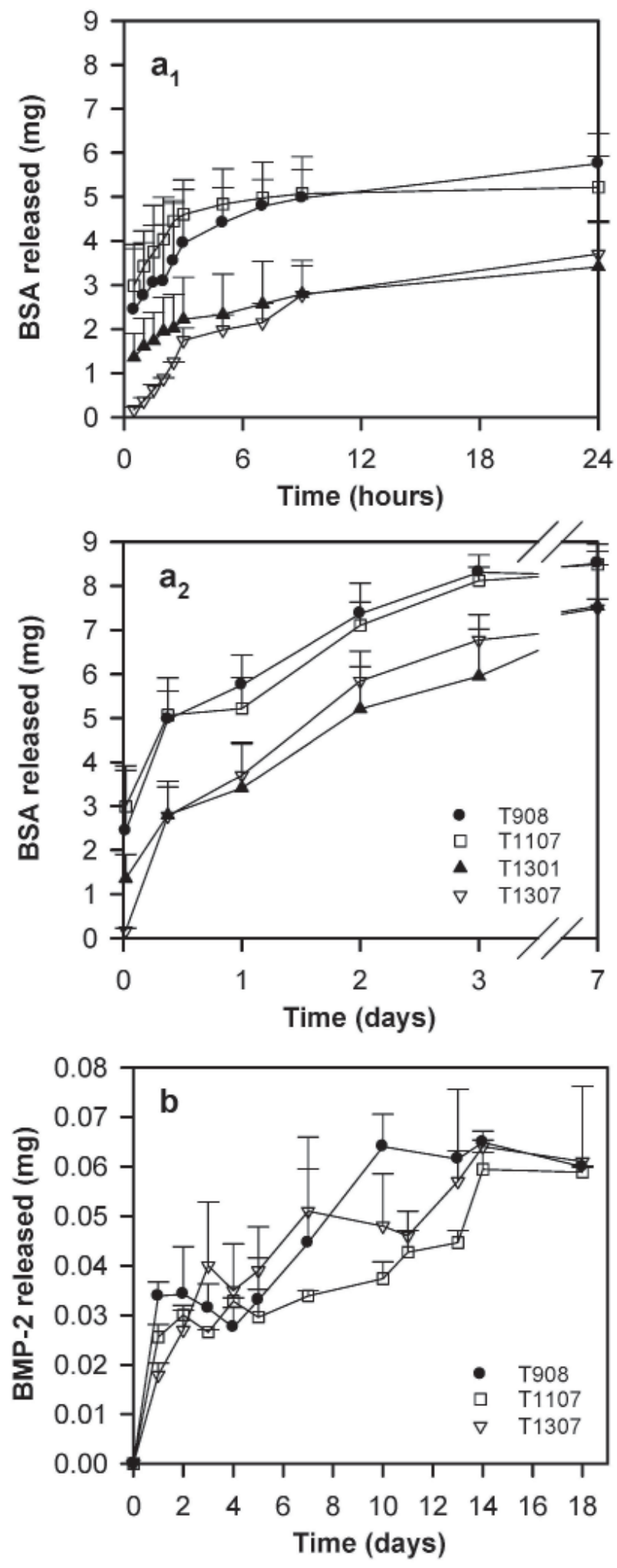

Fig. 5. BSA ( $\mathbf{a}_{1}$, up to $24 \mathrm{~h}$, and $\mathbf{a}_{2}$, up to $7 \mathrm{~d}$ ) and rhBMP-2 (b) release profiles from $20 \% \mathrm{w} / \mathrm{w}$ poloxamine gels in phosphate buffer $\mathrm{pH} 7.4$ at $37^{\circ} \mathrm{C}$. In the case of rhBMP-2, the release medium was supplemented with sodium azide $(0.02 \% \mathrm{w} / \mathrm{v})$. The data plots only show one standard deviation in order to reduce overlapping. 


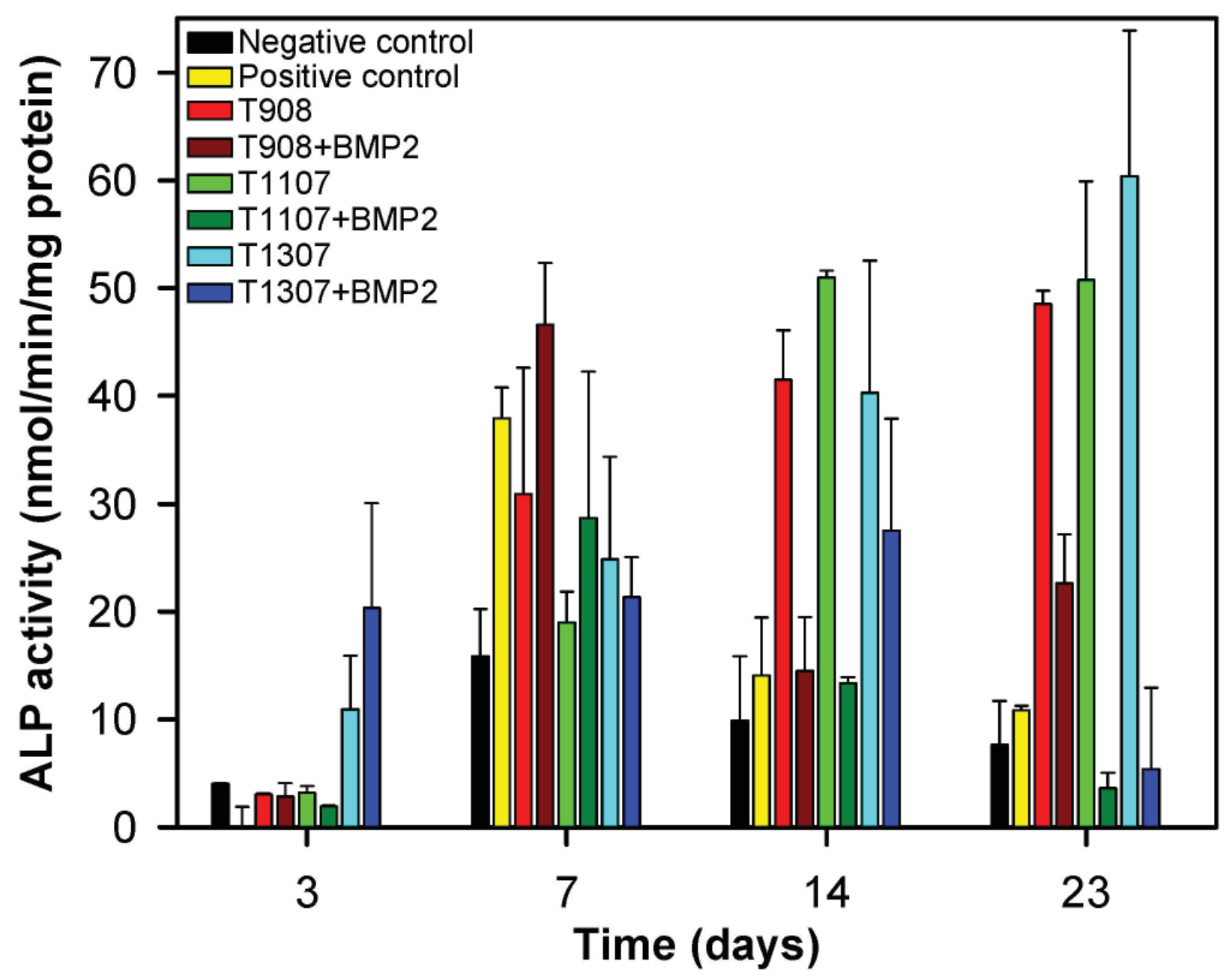

Fig. 6. Stimulation of ALP activity in mesenchymal stem cells induced by rhBMP-2-loaded poloxamine gels or by poloxamine solely gels. Bioactivity of positive (standard osteoinductive medium) and negative (cells alone) controls are also shown. Data are shown as mean + S.D.; $n=4$.

2 , but the relative amounts of cells, polymer, and medium were increased 4, 1.67, and 3-fold in the Tetronic 1301 experiments compared to those carried out with Tetronic 908, 1107 and 1307. Volume restrictions in the 6-well plate Transwell ${ }^{\circledR}$ prevented the use of a greater volume of Tetronic 1301 solution and medium.

\section{Sol-to-gel phase transitions}

The dependence of viscoelastic parameters on temperature of $20 \% \mathrm{w} / \mathrm{w}$ poloxamine in phosphate buffer $\mathrm{pH} 7.4$ and in D-MEM culture medium is shown in Fig. 4 a and b, respectively. At room temperature, Tetronic 908, 1107 and 1307 systems only exhibited low G" modulus, with values below $1 \mathrm{~Pa}$. Tetronic 1301 was the only with recordable G' values, but as observed for the other poloxamines $G^{\prime}$ and G" moduli were below $1 \mathrm{~Pa}$. As temperature increased, a sudden increase in both moduli occurred. The gel temperature (at which the G' and G' crossover occurred) in phosphate buffer $\mathrm{pH} 7.4$ was around $25^{\circ} \mathrm{C}$ for Tetronic 1107, 1301 and 1307, and $33{ }^{\circ} \mathrm{C}$ for Tetronic 908 (Fig. $4 a)$. Slightly greater gel temperature values were recorded for poloxamine dispersions prepared in D-MEM culture medium (Fig. 4b). Above the gel temperature and up to $45^{\circ} \mathrm{C}$, the moduli slightly increased or reached a plateau, which is characteristic of well-structured networks. G' values in that region ranged between $10^{3}$ and $10^{5} \mathrm{~Pa}$, as observed for $20 \% \mathrm{w} / \mathrm{w}$ Pluronic F127 systems. Poloxamine dispersions were evaluated again after being autoclaved and the rheological profiles (data not shown) were superimposable upon those obtained before autoclaving.

\section{BSA release}

Poloxamine systems $(20 \% \mathrm{w} / \mathrm{w})$ containing BSA were placed in test tubes, thermostatically controlled at 37 ${ }^{\circ} \mathrm{C}$, and when the temperature was stabilized, phosphate buffer $\mathrm{pH} 7.4$ (also at $37^{\circ} \mathrm{C}$ ) was slowly deposited on the surface of formulations. During the first three days of the experiment, two well differentiated phases (i.e., the gel at the bottom and the buffer on it) were clearly observed. After that time, the gel mixed with the medium and eventually became diluted in the buffer. Formulations containing Tetronic 908 or 1107 released 50\% BSA in the first $5 \mathrm{~h}$, while those prepared with Tetronic 1301 and 1307 released around $25 \%$ BSA in the same time (Fig. $5 \mathrm{a}_{1}$ ). Then, the release was sustained up to $7 \mathrm{~d}$ at an almost constant rate (Fig. 5a $\mathrm{a}_{2}$ ). Tests carried out using poloxamine dispersions at greater concentration $(25 \% \mathrm{w} / \mathrm{w})$ did not reveal relevant changes in BSA release profiles. 

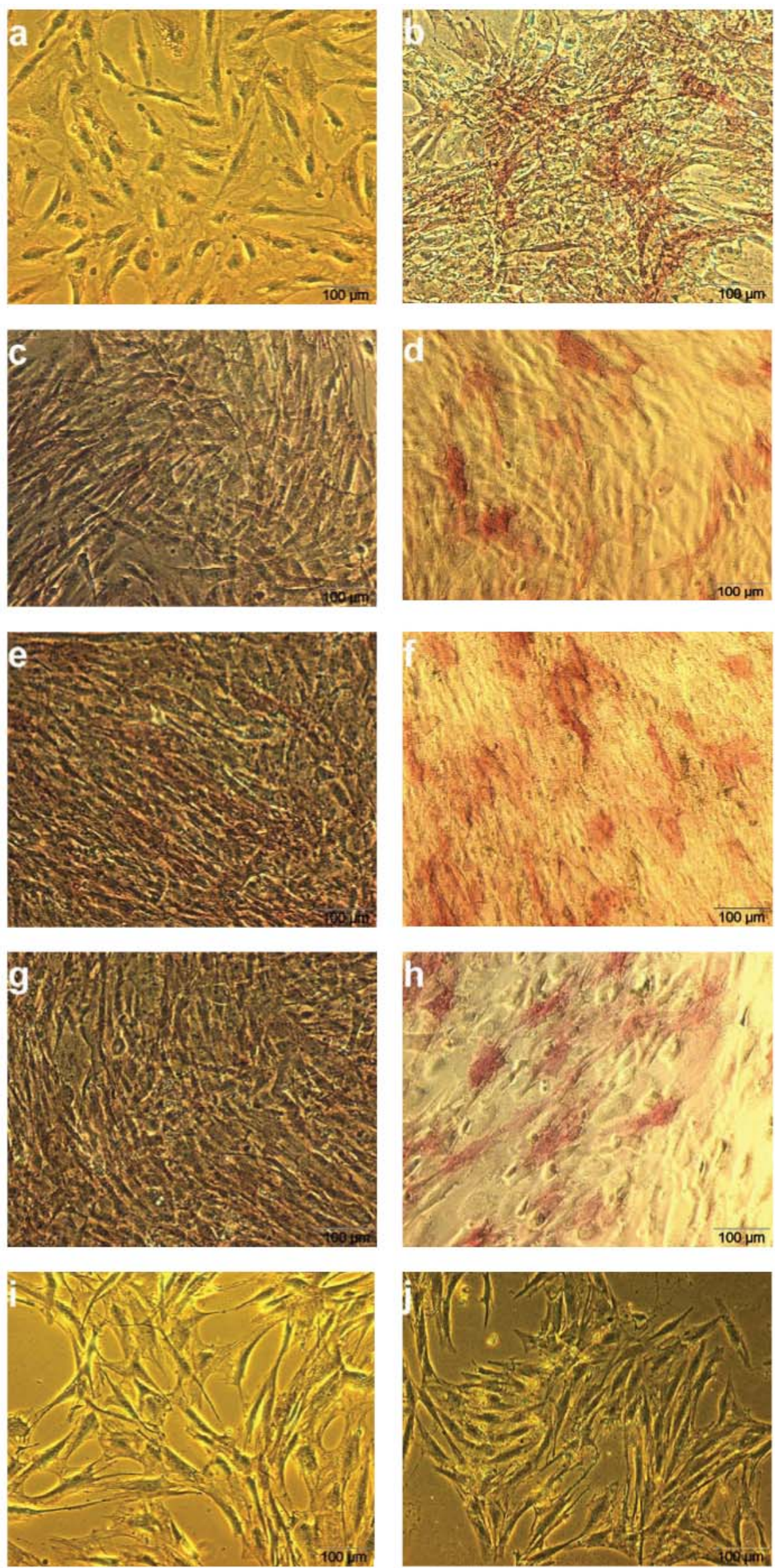

Fig. 7. ALP staining of cells at 14 days in control medium (a), osteogenic medium (b), and in the presence of gels of Tetronic 908 solely (c) and with rhBMP-2 (d), Tetronic 1107 solely (e) and with rhBMP-2 (f), Tetronic 1307 solely (g) and with rhBMP-2 (h), and Pluronic F127 solely (i) and with rhBMP-2 (j). 


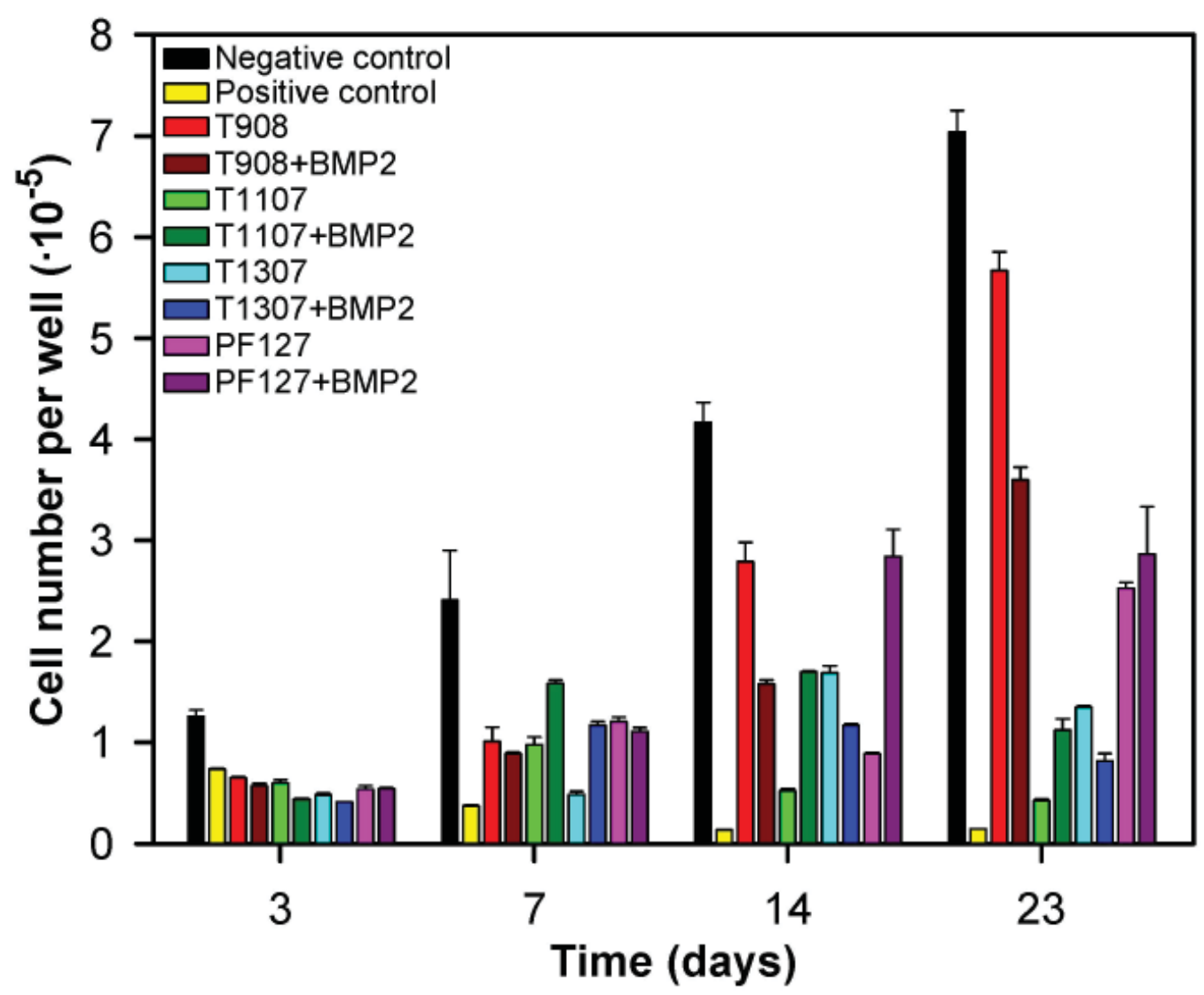

Fig. 8. Time-evolution of cell proliferation (determined using MTT assay and mesenchymal stem cells) in MesenPRO $\mathrm{RS}^{\mathrm{TM}}$ culture medium (negative control), osteogenic medium (positive control) and in the presence of poloxamine or poloxamer gels solely or loaded with rhBMP-2.

\section{rhBMP-2 release and bioactivity tests}

Commercial rhBMP-2 solution was readily mixed with concentrated poloxamine dispersions to render a rhBMP-2 concentration of $0.037 \mathrm{mg} / \mathrm{mL}$ in $20 \% \mathrm{w} / \mathrm{w}$ poloxamine solutions. Similarly prepared formulations were used for the in vitro release tests, bioactivity and gene expression assays. Since Tetronic 1301-based gels exhibited phase separation from the culture medium during the bioactivity assay, these formulations were discarded for further studies. The release experiments were carried out in phosphate buffer containing sodium azide $(0.02 \% \mathrm{w} / \mathrm{v})$. Active rhBMP-2 was specifically quantified using a sandwich enzyme immunoassay technique (Quantikine BMP-2 Immunoassay, R\&D Systems USA). rhBMP-2 in vitro release profiles are shown in Fig. 5b. As observed for BSA release profiles, a fast delivery of rhBMP-2 occurred in the first day (amount released ranked in the order Tetronic 908 $>1107>1307)$ followed by a slower release for two weeks (100\% release was achieved).

The bioactivity of rhBMP-2 released from poloxamine gels was assessed by monitoring the ALP activity of mesenchymal stem cells (Fig. 6). Pluronic F127 was also tested at the same concentration as the poloxamines. Negative (cells in medium without additives) and positive (cells in osteogenic differentiation medium) control assays were carried out as well. Negative controls revealed that the ALP activity of mesenchymal cells slightly increased at day 7 , returning then to basal values. The ALP activity of the cells cultured in the osteogenic medium (positive control) showed a maximum at day 7 , which was much more intense than that observed for the negative control. ANOVA test of ALP activity at day 7 showed significant differences when all systems were compared $\left(\mathrm{F}_{8,9 \text { d.f. }}=\right.$ 5.27; $\alpha<0.05)$. LSD tests indicated that the ALP activity of Pluronic F127 solely, Tetronic 1107 solely and Tetronic 1307 with rhBMP-2 was no different from that of negative control.

Cells cultured with Tetronic 908 and 1107 gels loaded with rhBMP-2 exhibited an ALP activity pattern that resembled that obtained with the osteogenic medium. By contrast, the ALP activity of cells cultured with Tetronic 1307 gel loaded with rhBMP-2 initiated at day 3, remained practically constant up to day 14, and then decreased (Fig. $6)$. The highest ALP activity at day 7 was obtained for Tetronic 908 gels with or without rhBMP-2. No statistically significant differences between these gels and the positive control were found.

Poloxamine gels by themselves (without rhBMP-2) induced a progressive increase in ALP activity up to day 14 or latter, rendering ALP activity values well above those observed for the positive control. The ALP activities of Tetronic 1307 with and without rhBMP-2 at day 14 were not statistically different (LSD test after ANOVA of all systems, $\left.\mathrm{F}_{8.9 \text { d.f. }}=12.08 ; \alpha<0.001\right)$. At day 23 , only cells cultured with poloxamines solely showed intense ALP activity; statistical test (LSD after ANOVA of all systems, 

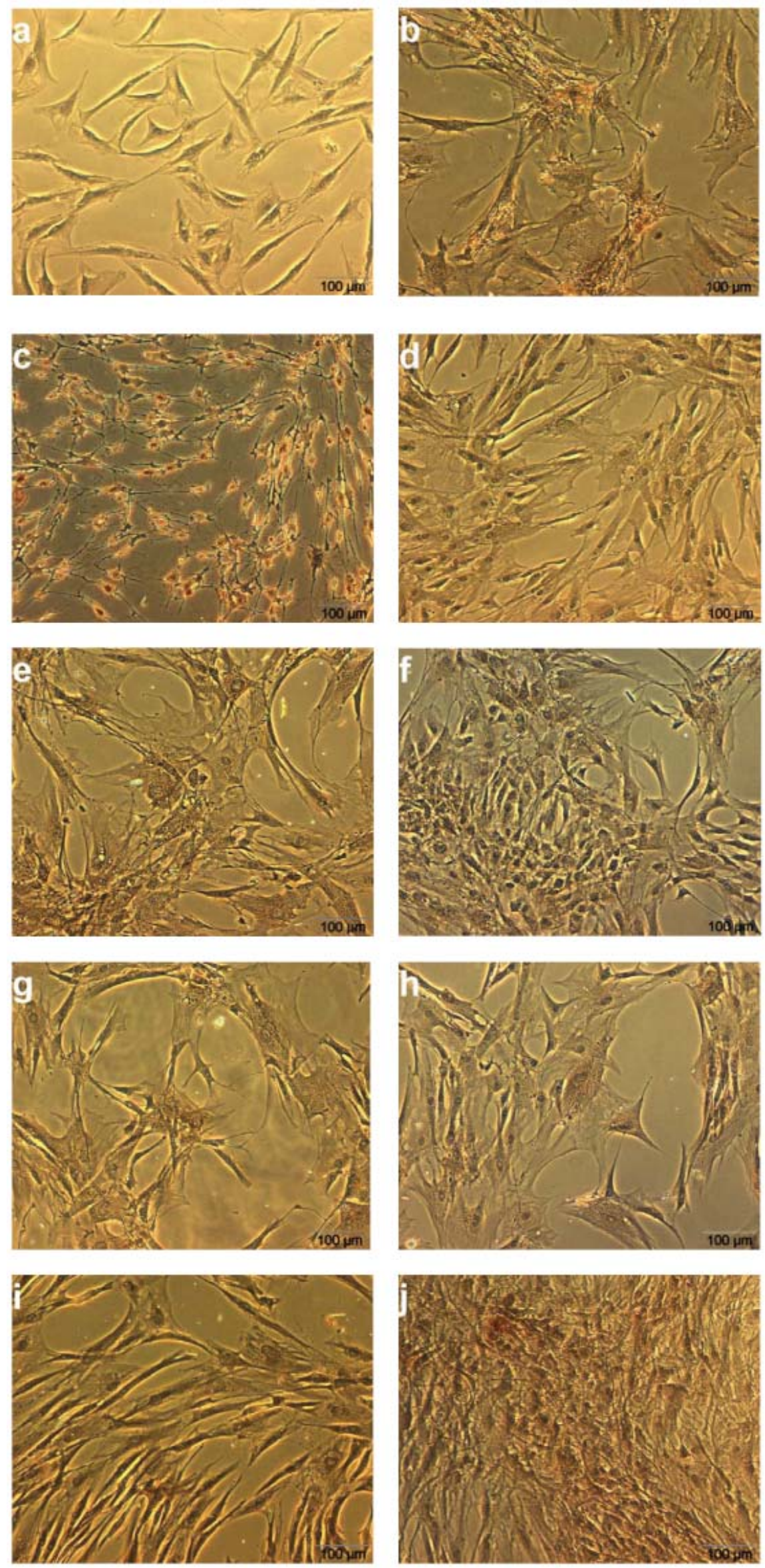

Fig. 9. Alizarin red staining of cells at $23 \mathrm{~d}$ in control medium (a), osteogenic medium (b), and in the presence of gels of Tetronic 908 solely (c) and with rhBMP-2 (d), Tetronic 1107 solely (e) and with rhBMP-2 (f), Tetronic 1307 solely (g) and with rhBMP-2 (h), and Pluronic F127 solely (i) and with rhBMP-2 (j). 

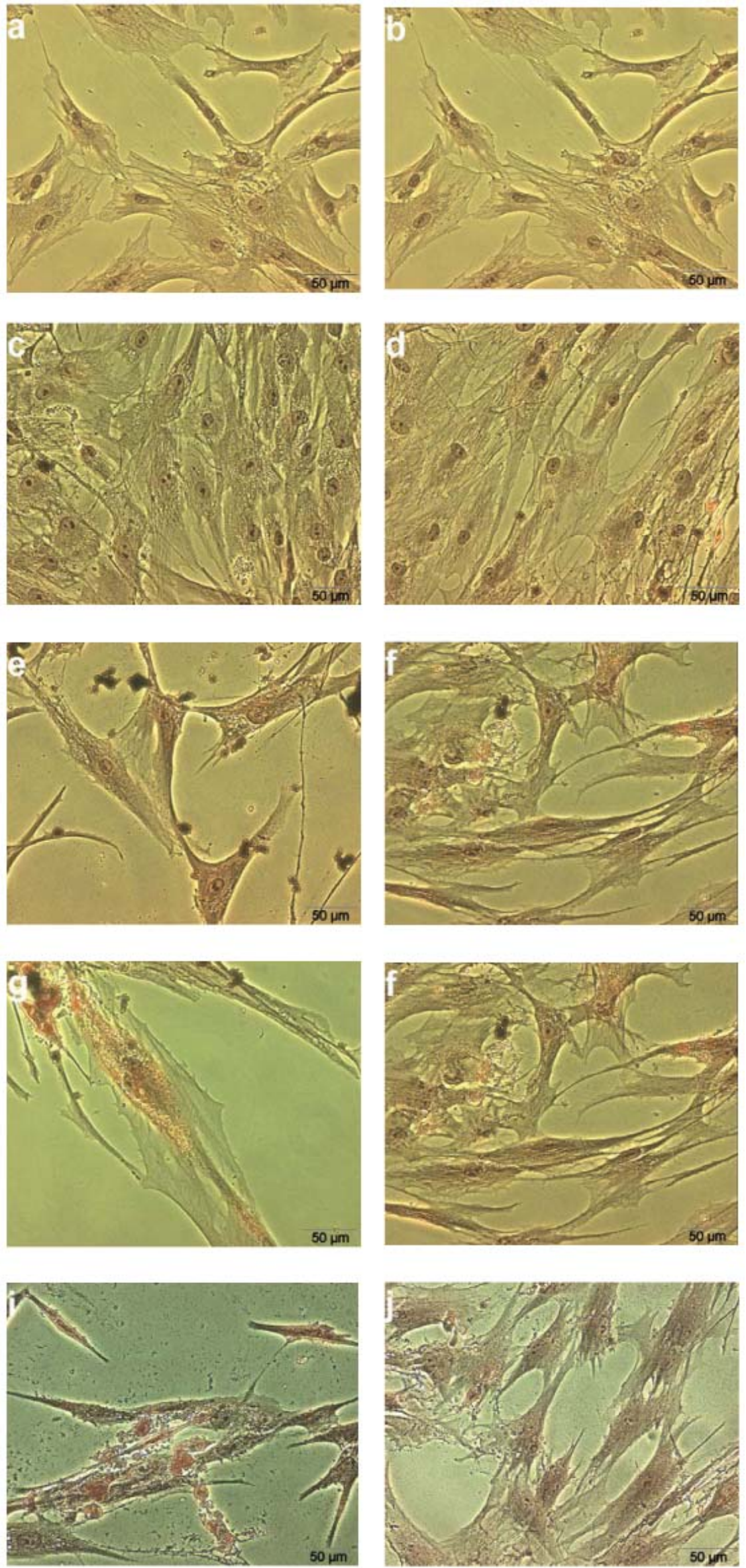

Fig. 10. Oil red staining of cells at $14 \mathrm{~d}$ with negative control (a,b), and in the presence of gels of Tetronic 908 solely (c) and with rhBMP-2 (d), Tetronic 1107 solely (e) and with rhBMP-2 (f), Tetronic 1307 solely (g) and with rhBMP-2 (h), and Pluronic F127 solely (i) and with rhBMP-2 (j). 

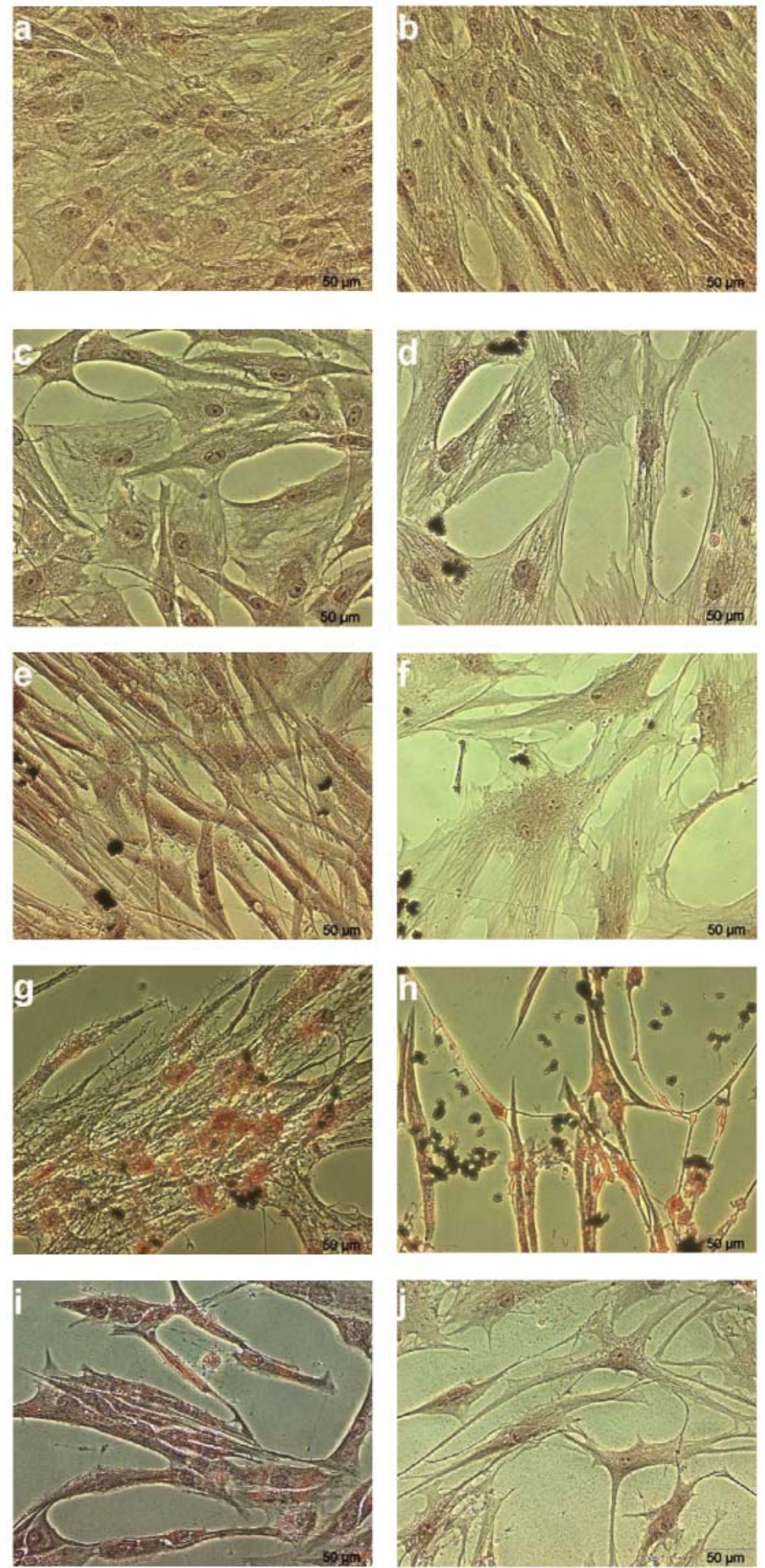

Fig. 11. Oil red staining of cells at $23 \mathrm{~d}$ with negative control (a,b), and in the presence of gels of Tetronic 908 solely (c) and with rhBMP-2 (d), Tetronic 1107 solely (e) and with rhBMP-2 (f), Tetronic 1307 (g) solely and with rhBMP-2 (h), and Pluronic F127 solely (i) and with rhBMP-2 (j). 

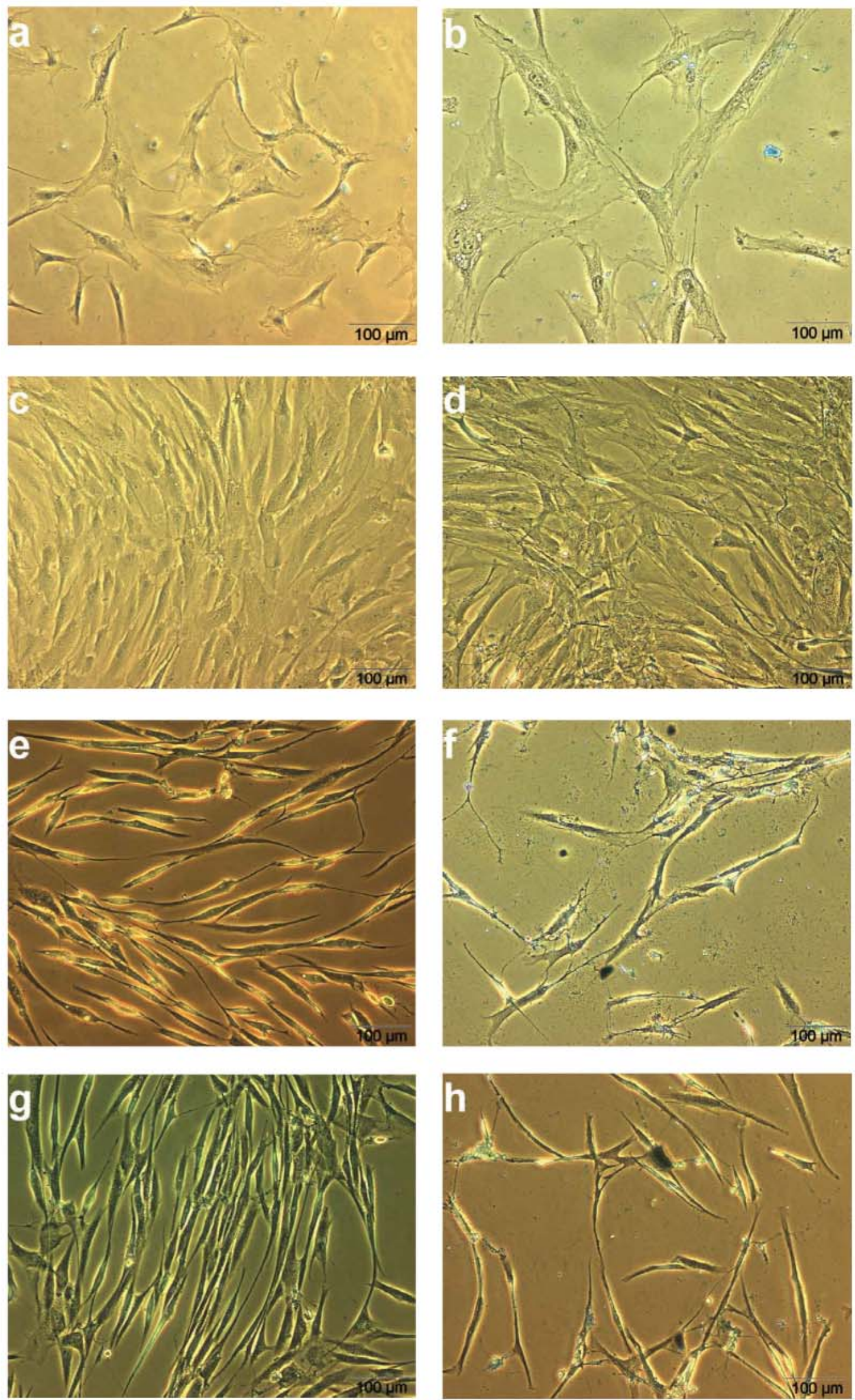

Fig. 12. Alcian blue staining of cells at $14 \mathrm{~d}$ with negative control (a,b), and in the presence of gels of Tetronic 908 solely (c) and with rhBMP-2 (d), Tetronic 1107 solely (e) and with rhBMP-2 (f), and Tetronic 1307 (g) solely and with rhBMP-2 (h). 

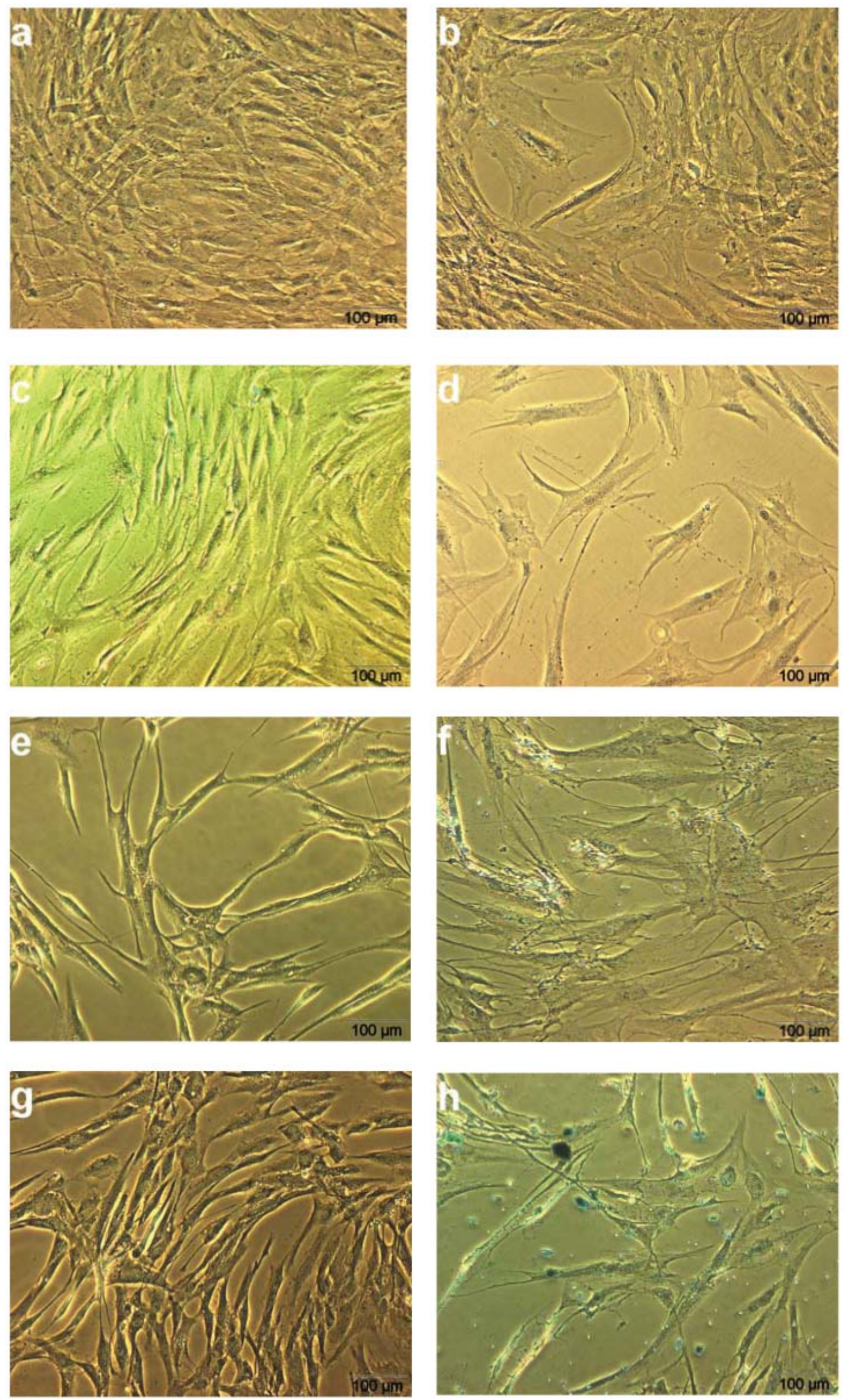

Fig. 13. Alcian blue staining of cells at $23 \mathrm{~d}$ with negative control (a,b), and in the presence of gels of Tetronic 908 solely (c) and with rhBMP-2 (d), Tetronic 1107 solely (e) and with rhBMP-2 (f), and Tetronic 1307 solely (g) and with rhBMP-2 (h). 

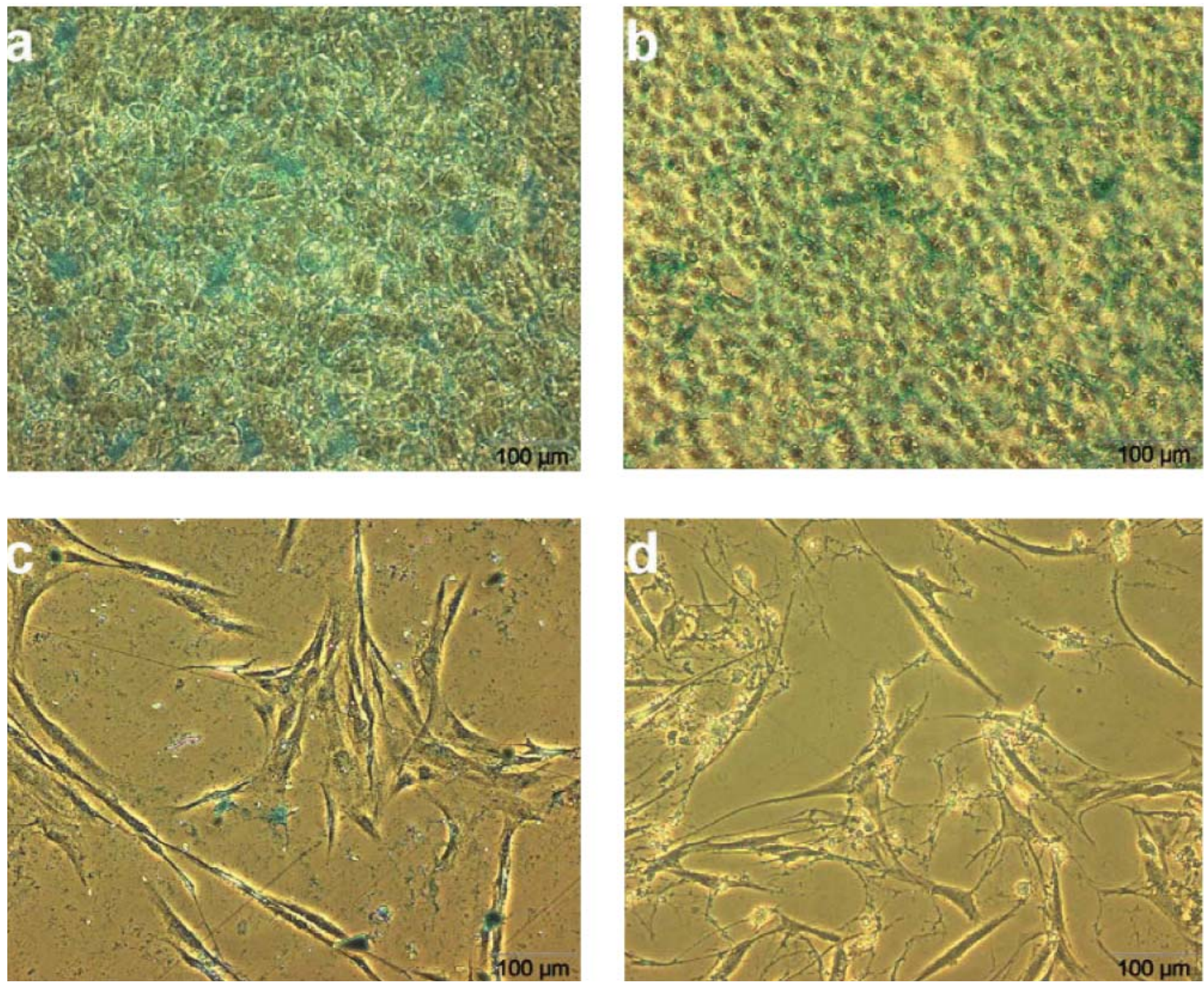

Fig. 14. Alcian blue staining at $14 \mathrm{~d}$ of chondrocytes $(\mathbf{a}, \mathbf{b})$ and of mesenchymal stem cells cultured and in the presence of gels of Pluronic F127 solely (c) and with rhBMP-2 (d).

$\left.\mathrm{F}_{8,9 \mathrm{df}}=15.36 ; \alpha<0.001\right)$ confirmed that Tetronic 908, 1107 and 1307 were different from the other systems. Such an intrinsic osteoinductive effect of poloxamines was not observed for poloxamer Pluronic F127 (ALP levels superimposable with those of the negative control), which is in agreement with previous reports (Clokie and Urist, 2000; Issa et al., 2008). ALP activity was also evaluated through histochemical staining as described below.

\section{Cell differentiation and mineralization}

Differentiation of mesenchymal cells to osteoblasts was visualized after ALP staining, using an inverted microscope (Fig. 7). In the negative control (no osteoinductive substance) the mesenchymal cells formed homogeneous monolayers, with a high proliferation index (Fig. 8). In the osteoinductive medium (positive control), the cells initially showed the typical spindle-shaped morphology of fibroblasts, but then the cell density diminished and the polygonal shape of osteoblasts was evident since day 7. Similarly, poloxamine gels loaded with rhBMP-2 caused differentiation to osteoblasts, which was evident at day 7 for Tetronic 908 formulations and at day 14 for the other poloxamine formulations (proliferation levels in between those of the negative and positive control, Fig. 8). On the other hand, poloxamine solely gels led to an initial proliferation of the mesenchymal cells (first week), followed by differentiation to osteoblasts (second to third week).

Alizarin red staining at days 14 and 23 is shown in Fig. 9. Cells cultured with rhBMP-2 loaded gels evidenced the staining typical of matrix mineralization at day 14 . Those treated with poloxamine solely gels did not show staining at day 14 but at day 23. No alizarin red staining occurred with Pluronic F127 solely gel. However, this poloxamer gel was highly adipogenic as observed after Oil Red O staining (Figs. 10 and 11). Cells treated with Tetronic 1307 gels solely or loaded with rhBMP-2 also evidenced a large number of lipid vesicles. Fewer vesicles were seen for Tetronic 1107 gels without rhBMP-2. No staining was observed with Tetronic 908, neither solely nor with rhBMP-2.

Alcian blue staining was negative for all cell cultures and formulations and no evidence of the typical extracellular matrix of chondrocytes with sulfated glycosaminoglycan was found (Figs. 12 and 13). Some minor blue points observed in photos of cells cultured in the presence of the poloxamines are artifacts caused by some residues of the staining. Furthermore, inverted optical microscopy observation of the cells did not reveal morphological changes of the mesenchymal cells to 


\begin{tabular}{|c|c|c|c|c|c|c|c|c|c|c|c|c|c|c|c|c|}
\hline \multirow{2}{*}{$\begin{array}{l}\text { Gel } \\
\text { Days }\end{array}$} & \multicolumn{2}{|c|}{ T908 } & \multicolumn{2}{|c|}{ T908+BMP2 } & \multicolumn{2}{|c|}{ T1107 } & \multicolumn{2}{|c|}{ T1107+BMP2 } & \multicolumn{2}{|c|}{ T1307 } & \multicolumn{2}{|c|}{ T1307+BMP2 } & \multicolumn{2}{|c|}{ PF127 } & \multicolumn{2}{|c|}{ PF127+BMP2 } \\
\hline & 4 & 7 & 4 & 7 & 4 & 7 & 4 & 7 & 4 & 7 & 4 & 7 & 4 & 7 & 4 & 7 \\
\hline CBFA-1 & & & & & & & & & & & & & & & & \\
\hline Collage & & & & & & & & & & & & & & & & \\
\hline GAPDH & & & & & & & & & & & & & & & & \\
\hline
\end{tabular}

\begin{tabular}{|l|ccccc|}
\hline Gel & \multicolumn{2}{c}{ Negative control } & \multicolumn{2}{c|}{ Positive control } & T908 \\
Days & 4 & 7 & 4 & 7 & 10 \\
\hline CBFA-1 & & & & \\
Collagen I & & & & & \\
& & & & & \\
GAPDH & & & & & \\
\hline
\end{tabular}

Fig. 15. Increase in osteogenic marker genes expression induced by poloxamines Tetronic 908, 1107 and 1307 and poloxamer Pluronic F127, both in the absence and in the presence of rhBMP-2. Osteogenic marker genes expression was observed using RT-PCR at various days. The expression of GAPDH was used to normalize gene expression levels.

chondrocytes (i.e., polyhedral shape; Moses et al., 1992) (Fig. 14 a,b). Pluronic F127 did not induce differentiation of mesenchymal stem cells to chondrocytes either (Fig. 14 $\mathrm{c}, \mathrm{d})$.

\section{Reverse transcription-polymerase chain reaction (RT-PCR) analysis}

Mesenchymal stem cells in culture medium (negative control) exhibited a basal expression of CBFA-1. Cells treated with Tetronic 908, 1107 and 1307 gels with and without rhBMP-2 increased mRNA expression of CBFA-1 in a time-dependent manner (Fig. 15). In the absence of rhBMP-2, the expression induced by Tetronic 1107 and Tetronic 1307 was evident at day 7, while with Tetronic 908 the induction was clearly observed latter, at day 10 . In the presence of rhBMP-2, the mRNA expression of CBFA-1 occurred at day 4 with Tetronic 1107 and 1307 and at day 7 with Tetronic 908 formulations.

Negative controls showed a moderate expression of the collagen type I marker, but a significant inductive effect was recorded for Tetronic 908 with and without rhBMP-2 (particularly relevant at day 10), and for Tetronic 1107 with rhBMP-2 and Tetronic 1307 both with and without rhBMP-2 at days 4 and 7. Correspondingly, cells cultured with Pluronic F127 did not show induction of these osteogenic marker genes at any time point of the study.

\section{Discussion}

\section{Cytocompatibility screening}

Poloxamines have received less attention than their linear counterpart poloxamers in the pharmaceutical and biomedical fields in general, but particularly as components of scaffolds or drug depots (Sosnik et al., 2008; AlvarezLorenzo et al., 2010b). Thus, the first step of the work was to gain an insight into the cytocompatibility of poloxamines and the incidence of their architecture variables (such as $\mathrm{EO} / \mathrm{PO}$ ratio and molecular weight) and to compare the data with those obtained with the related poloxamers. Namely eight varieties of Tetronic were chosen to cover from 1,650 to 25,000 Da molecular weight range and from 0.15 to 5.27 $\mathrm{EO} / \mathrm{PO}$ units ratio (Table 1). For comparison purposes we have chosen Pluronic F127, which has been already used as inactive ingredient of approved drug products and possess a molecular weight similar to that of Tetronic 1107 and relative weight content in EO of around $70 \%$ as Tetronic 1107 and 1307 (Table 1).

Balb/3T3 fibroblasts and CHO-K1 epithelial-like cells are widely used for the testing of new biomaterials, but fibroblasts are more demanding regarding nutritional conditions and more sensitive to toxic agents (Park et al., 2002). Poloxamine concentrations were chosen to cover a wide range of values below and above the critical micellar concentrations (CMC), which are around $0.7 \%$ for Tetronic 901, 904 and 150R1, 1\% for Tetronic 1107, 1301 and 1307, and 2\% for Tetronic 304 and 908 (GonzalezLopez et al., 2008). No clear dependence of cell viability on $\mathrm{CMC}$ values was noticed. As a general trend, the hydrophilic poloxamines were more cytocompatible than the hydrophobic ones, showing better cytocompatibility as their molecular weight increases (Fig. 2). The lower cytocompatibility observed for Tetronic 901 and 904 can be related to their relatively low molecular weight and high hydrophobicity, which may enable the copolymer chains to intercalate in the cell membranes causing some disruption, as reported for Pluronic L61 of 2000 Da and HLB 1-7 (Exner et al., 2005). The high cytotoxicity 
recorded for Tetronic 904 at $72 \mathrm{~h}$ is in agreement with our previous observation of the deleterious effect of Tetronic 904 on Caco-2 monolayers integrity (Alvarez-Lorenzo et al., 2010a). Cytotoxicity is commonly evaluated using the $0,1,2,3$ and 4 scale, which corresponds to $>90 \%, 70$ $90 \%, 40-70 \%, 10-40 \%$, and $<10 \%$ cell counts compared to control growth (Xian, 2009). The positive control had a cytotoxicity scale of 4 . An acceptable level of viability is of 0 or 1 in the scale, and most poloxamines fulfilled that score at $24 \mathrm{~h}$ except Tetronic 304 and 904 at the highest concentrations evaluated. After $72 \mathrm{~h}$, Tetronic 901 and 904 had scores of 2 and 4, respectively, against CHO-K1 cells. In the case of Balb/3T3 the score of 0 or 1 was maintained by Tetronic 908 at any concentration and by Tetronic 304, 1107, 1301, 1307 and 150R1 except at the highest concentrations tested. Taking into account the cytocompatibility results, Tetronic 908, 1107 and 1307 were chosen as representatives of hydrophilic poloxamines and Tetronic 1301 as representative of the hydrophobic varieties for further studies.

Pluronic F127 showed high cell viability at $24 \mathrm{~h}$, disregarding the copolymer concentration, but at $72 \mathrm{~h}$ a marked dose-dependence was observed, leading to values similar to those of Tetronic 1107 against Balb/3T3 fibroblasts and those of Tetronic 901 against CHO-K1 cells. It has been previously reported that poloxamer varieties show certain cell toxicity, which is particularly evident when the concentration surpasses the CMC. This effect has been related to the increase in the fluidity of the cell membrane, the inhibition of efflux pumps and cell detoxification mechanisms, and the depletion of intracellular ATP (Exner et al., 2005; Krupka et al., 2009).

Experiments with SAOS-2 cells (a human osteoblast cell line) revealed that Tetronic 908, 1107, 1301 and 1307 at the concentration required for the in situ gelling $(20 \% \mathrm{w} / \mathrm{w})$ lead to viability above $90 \%$ (Fig. 3). Although the four poloxamines could not be tested under exactly the same experimental conditions and the direct comparison of the cytotoxicity data may be not rigorous, the results obtained prove that these poloxamines are highly cytocompatible. Thus, Tetronic 908, 1107, 1301 and 1307 may be suitable for developing injectable scaffolds.

\section{Temperature-induced gelling and BSA control release} Below $20{ }^{\circ} \mathrm{C}, 20 \% \mathrm{w} / \mathrm{w}$ poloxamine solutions behaved as free flowing liquids and were easily syringeable owing to their low viscosity. An increase in temperature led to an increase in the viscosity of the systems and for them to undergo a sol-to-gel transition, driven by hydrophobic interactions among PPO blocks and packing of the micellar aggregates (Fig. 4 a,b). The greater gel temperature of Tetronic $908\left(33^{\circ} \mathrm{C}\right)$, compared to Tetronic 1107, 1301 and $1307\left(25^{\circ} \mathrm{C}\right)$, is due to its longer PEO blocks, which enhance the hydrophilicity of the copolymer. At $37^{\circ} \mathrm{C}$, all systems behave as gels with storage modulus values $\left(10^{3}\right.$ $10^{5} \mathrm{~Pa}$ ) similar to those we obtained for Pluronic F127 and to those previously reported for other in situ gelling systems and syringeable depots for drug delivery (Chaibundit et al., 2007; Jones et al., 2009). The storage modulus values are also in the range of those found for preformed bone scaffolds such as hydroxyapatite-atelocollagen composites (Pelin et al., 2009). Poloxamine dispersions prepared in culture medium (D-MEM) behaved similarly to those prepared in phosphate buffer $\mathrm{pH} 7.4$, although the gel temperature was slightly greater in D-MEM (Fig. 4b), due to the different nature of the salts present in both media. Importantly, autoclaving did not modify the rheological behavior of $20 \% \mathrm{w} / \mathrm{w}$ Tetronic solutions, which indicates that this method is suitable for sterilizing the injectable scaffolds. In general, the information available about the incidence of thermal treatments on the viscoelasticity of PEO-PPO block copolymer solutions is scarce, but it has been reported that Pluronic F127 stands quite well autoclaving (Woerle et al., 2006). Nevertheless, even if the terminal sterilization by autoclaving would not be adequate for the Tetronic systems (e.g., owing to presence of a labile active substance, such as a peptide or protein), their low viscosity at $4{ }^{\circ} \mathrm{C}$ makes sterilization by filtration possible.

Once $20 \%$ poloxamine systems were shown to be able to undergo sol-to-gel transitions at temperature below but near to $37^{\circ} \mathrm{C}$, their ability to sustain the delivery of BSA was tested. BSA is commonly used as model protein, owing to its availability and recognized high stability in aqueous media (Hedoux et al., 2009). The release test was performed in such a way that the gel was already formed when it entered into contact with the release medium, and the surface of contact $\left(143.1 \mathrm{~mm}^{2}\right)$ was initially the same for all formulations. Release profiles showed a burst (first $5 \mathrm{~h}$ ) followed by a gradual release for one week. The burst was especially sharp in the case of the most hydrophilic poloxamines (Fig. 5a $)$. The slower delivery of BSA from Tetronic 1301 and 1307 systems may be related to their lower gel temperature, which makes the gel withstand better the progressive dilution by the release medium. An increase in poloxamine concentration did not lead to a significant decrease in the burst effect. For any formulation, the gels mixed completely with the release medium after $3 \mathrm{~d}$, which indicates that under the test conditions the mean erosion/dissolution rate of the formulations is around $3.2 \times 10^{-4} \mathrm{~g} / \mathrm{min} / \mathrm{cm}^{2}$. This value is lower than that reported for Pluronic gels tested using greater interfacial area and under stirring conditions, namely $0.016 \mathrm{~g} / \mathrm{min} /$ $\mathrm{cm}^{2}$ (Anderson et al., 2001).

\section{rhBMP-2 release, bioactivity and gene expression}

Optimal therapeutic dose of rhBMP-2 in human is difficult to establish because of the remarkable speciesspecific dose response, which makes results with animal models difficult to extrapolate to humans (Luginbuehl et al., 2004), and because of the up-regulation of BMP inhibitors that may interfere in the healing mechanisms (Westerhuis et al., 2005; Bessa et al., 2008). The rhBMP-2 concentration chosen $(0.037 \mathrm{mg} / \mathrm{mL})$, which is in between the nanogram $/ \mathrm{mL}$ range of the physiological growth factors and the milligram $/ \mathrm{mL}$ range of current human therapeutic formulations (Luginbuehl et al., 2004), has been shown to be suitable for in vitro and in vivo activity (Wang et al., 1990; Kim and Valentini, 2002). It has been previously shown that BMP-2 is highly unstable in phosphate buffer, needing the addition of protease inhibitor and germicide 
substances to prevent a fast degradation (Hsieh et al., 2006). Therefore, the release medium was supplemented with sodium azide $(0.02 \% \mathrm{w} / \mathrm{v})$. In parallel to the in vitro release tests, bioactivity and gene expression assays were carried out. We observed that Tetronic 1301 gels underwent a remarkable phase separation from the culture medium during the bioactivity assay and, consequently, this hydrophobic poloxamine was discarded for further studies.

Despite that rhBMP-2 $(18-30 \mathrm{kDa})$ is a protein smaller than BSA (67 kDa), rhBMP-2 release profiles resembled to some extent those of BSA (Fig. 5). Thus, the slow erosion/dissolution of the gels makes the control of rhBMP-2 release possible, being poloxamine gels as efficient as, or even more than, non-syringeable complex matrices reported as BMP-2 eluting scaffolds (Rai et al., 2005; Hsieh et al., 2006). Previous studies have shown that efficient scaffolds should combine a reasonably high initial release with a sustained delivery behavior latter on (Uludag et al., 1999). Although the current state of the art indicates that there is not one single pharmacokinetic profile predictive of success, it is apparent that the extremes of release rates (bolus injections or prolonged low level release) are not beneficial to bone induction (Geiger et al., 2003). rhBMP-2 release rate in vivo from poloxamine systems is expected to occur at slower rates than in vitro, because the smaller volume of medium and the quasi-static conditions. Nevertheless, the sustained delivery for almost two weeks observed in vitro (Fig. 5b) resembles to some extent to the in vivo profile reported for the commercially available collagen sponge-based rhBMP-2 formulations (Li and Wozney, 2001). Due to the temperature-induced gelling, poloxamine formulations are suitable for preparing injectable formats that enable minimally invasive application without requiring an open procedure, as most biodegradable and non-biodegradable matrices demand. Furthermore, formulation of rhBMP-2 in poloxamine systems under mild conditions has the advantage of avoiding the loss of biological activity of the growth factor, which usually happens during formulation processes that involve harsh conditions, such as heating, sonication and organic solutions. Bioactivity assays were also carried out to gain insight into this aspect.

Mesenchymal stem cells cultured in non-osteogenic medium (negative control) showed certain ALP activity, with a maximum at day 7 , as previously reported (Harris et al., 2004). Cells cultured in medium with Pluronic F127 solely, Tetronic 1107 solely and Tetronic 1307 with rhBMP-2 showed at day 7 an ALP activity not statistically different from that of the negative control. By contrast, ALP activity in the presence of Tetronic 908 and 1107 gels loaded with rhBMP-2 resembled that achieved with the osteogenic medium, with a maximum at day 7 (Kim and Valentini, 2002). Tetronic 1307 gel loaded with rhBMP-2 caused an increase in ALP activity since day 3, which remained practically constant for two weeks (Fig. 6). The differences in ALP activity recorded for the gels loaded with rhBMP-2 are related to the different ability of poloxamines to regulate the release of rhBMP-2 in its bioactive form. Compared to Tetronic 908 and 1107 formulations, Tetronic 1307 gel showed the most sustained delivery of protein. This slower release may lead to, given a longer time, protein in the culture medium available for inducing cell differentiation, resulting in a prolonged plateau in ALP activity (Fig. 6).

The osteoinductive capability of the three poloxamines on their own was clearly seen when the cells were cultured in the presence of gels that did not contain rhBMP-2 (Fig. 6). For example, Tetronic 908 solely gels rendered ALP activity at day 7 as high as the osteogenic medium. This behavior contrasts with that of Pluronic F127, which did not cause any increase in the ALP activity of the mesenchymal stem cells. The remarkable ALP activity of poloxamine alone solutions can be related to its structural similarities with certain natural polyamines, such as spermine and spermidine. Natural polyamines are essential for a number of functions in the cell, including proliferation and apoptosis; however, their explicit role in these cellular processes is mostly unknown (Helder and Wuisman, 2007). Particularly, polyamines at concentrations in the range of $1 \mathrm{nM}$ to $100 \mu \mathrm{M}$ have been recently shown to induce proliferation and differentiation of stem cells (Helder and Wuisman, 2007). Furthermore, since it is well known that the alkaline phosphatases are most effective in an alkaline environment (Wahlstroem et al., 2007), the base-like character of polyamines and poloxamines may assist their osteoinductive performance. The osteogenic efficiency of poloxamines by themselves was confirmed in further studies described below. The slower bioactivity of poloxamine solely gels (compared to those loaded with rhBMP-2) correlates with the fact that the copolymer depot erodes/dissolves in the cell culture medium more slowly than rhBMP-2 is released. Once differentiation occurs, the ALP activity returns to basal levels. This explains why various maxima in the ALP activity were not observed for rhBMP2-loaded poloxamine gels. The ALP activity induced by poloxamine gels both with and without rhBMP-2 was clearly visualized by cell histochemical staining at day 14 (Fig. 7). Such an osteogenic activity of poloxamines may offer novel perspectives in the field of the fracture healing, overcoming the safety and the cost/ effectiveness concerns associated to the large scale clinical use of recombinant growth factors.

In contrast to that observed in the absence of osteoinductive agents, mesenchymal stem cells in the osteoinductive medium (positive control) did not proliferate but differentiated to osteoblasts (Fig. 8). This finding is in agreement with the typical increase in cell apoptosis and decrease in cell proliferative activity observed during osteogenic induction in vitro, due to the biochemical stress underwent by the cells in the osteoinductive medium (Niemeyer et al., 2006; Li et al., 2009). Poloxamine gels loaded with rhBMP-2 showed an intermediate behavior, combining proliferation and differentiation to osteoblasts. The earlier differentiation induced by Tetronic 908 formulations (evident since day 7) compared to the other formulations (seen at day 14) can be explained by the greater ALP activity at day 7 of cells cultured with Tetronic 908 gels loaded with rhBMP-2 (Fig. 6). Interestingly, poloxamines alone (without rhBMP-2) caused proliferation of the mesenchymal cells for the first week, and then differentiation to osteoblasts for the second to the third week. It should be noticed that Tetronic 908 
rendered the gels with the highest proliferation level and osteoinductive capacity.

The poloxamine gels loaded with rhBMP-2 induced matrix mineralization already at day 14 (Fig. 9). This finding confirmed that the cells had previously differentiated to osteoblasts, which are able to start the formation of bone matrix and to regulate the deposition of salts. Mineralized nodules were also clearly seen in the cultures with poloxamine solely gels, although at latter time $(23 \mathrm{~d})$ due to the on-going differentiation of the cells to osteoblasts (Jaiswal et al., 1997). By contrast, Pluronic F127 solely gels were not able to induce matrix mineralization.

Since mesenchymal stem cells can give rise to the progenitors of various cell lineages (Yin et al., 2010), differentiation into adipocytes and chondrocytes was also assessed using Oil Red $\mathrm{O}$ and Alcian blue staining, respectively. Several previous studies have shown that rhBMP-2 can induce differentiation of mesenchymal stem cells to adipocytes (Ji et al., 2000; Date et al., 2004; Kato et al., 2009). Furthermore, it has been reported that certain poloxamer varieties promote adipogenic differentiation of mesenchymal stem cells from bone marrow (Vashi et $a l ., 2008)$. To gain an insight into these aspects, we tested Pluronic F127 under the same conditions as poloxamines. This poloxamer was highly adipogenic, as was also the case for Tetronic 1307 systems, without or with rhBMP-2 (Figs. 10 and 11). This finding is in agreement with the smallest alkaline phosphatase activity recorded with Tetronic 1307 formulations. Some lipid vesicles stained with Oil Red $\mathrm{O}$ were also observed in the presence of Tetronic 1107 gels without rhBMP-2, but to a much lower extent than in the case of Tetronic 1307. None of the Tetronic 908 formulations were adipogenic. Although, according to the analysis on the supplier's data sheet Tetronic 908 is the largest poloxamine with an average molecular weight of 25,000 (see Table 1), it has been reported that different batches of commercial copolymers may differ remarkably from each other in mean molecular weight and polydispersity (Moghimi et al., 2001; Al-Hanbali et al., 2007). Analytical method and conditions may also affect to the results. This is particularly so for GPC analysis of the poloxamine batches used in the present study and under the conditions reported by Chiappetta et al. (2010) rendered average-number molecular weights of 9,600, 11,600 and 11,700 for Tetronic 908, 1107 and 1307 , respectively. According to these experimental results, Tetronic 1307 appears to be the largest poloxamine and, consequently, the contribution of the diamine group to its osteoinductive activity may be shielded at a greater extent by the long EO-PO copolymer arms than in the case of the other poloxamines. Alcian blue staining tests revealed that neither poloxamines nor Pluronic F127 induced differentiation of mesenchymal stem cells to chondrocytes (Fig. 14).

Finally, osteogenic marker gene expression was analyzed to confirm the osteoblastogenesis induction (Trentz et al., 2010). CBFA-1 (Runx-2), an osteoblast specific transcription factor, essential for developing a mature osteoblast phenotype, has been identified as the only transcriptional factor responsible for osteoblastic differentiation and expression of osteocalcin and osteopontin (Hing et al., 2004). In agreement with data shown in Fig. 6 and also with previous reports (Zuk et al., 2002), mesenchymal stem cells exhibited a basal expression of CBFA-1. Tetronic 908, 1107 and 1307 gels with and without rhBMP-2 increased mRNA expression of CBFA-1, although earlier in the presence of rhBMP-2 (Fig. $15)$. Both with and without rhBMP-2, the induction was observed later for Tetronic 908 than for Tetronic 1107 and 1307, which is in agreement with the high cell proliferation caused by Tetronic 908 .

It is well-known that initial collagen matrix accumulation is essential for sequential expression of the differentiation related proteins, e.g. alkaline phosphatase, bone sialoprotein, and osteocalcin (Hutmacher and Sugunan, 2004). Again, all gels induced the expression of collagen type I marker, but Tetronic 908 ones with and without rhBMP-2 did it later. Induction was not observed with Pluronic F127. This finding may be related to the capability of the linear poloxamer to induce adipogenic differentiation, as observed with the bioactivity and histochemical analysis described above. The central ethylenediamine group in the X-shaped structure of poloxamines seems to be crucial for the osteoinductive capability of Tetronics. No other polymer has been previously reported to be osteoinductive by itself.

\section{Conclusions}

Various poloxamine varieties (Tetronic 908, 1107, 1301 and 1307) combine good cytocompatibility with the ability to undergo sol to gel transitions at near to body temperature. Moist heat sterilization (autoclaving) does not alter the rheological properties of the copolymer solutions, which is an important aspect for the development of injectable scaffolds. In situ formed poloxamine gels can sustain the delivery of proteins at $37^{\circ} \mathrm{C}$ (BSA and rhBMP-2) for several days; the release rate being tuneable by the hydrophilicity and the molecular weight of the copolymer. The initially rapid release of an important amount of rhBMP-2 followed by a slower release enables the gels to exhibit a marked ALP activity at day 7 and the matrix mineralization at day 14. As a remarkable novel finding, poloxamines themselves induced the proliferation of mesenchymal cells and then their differentiation to osteoblasts, although more slowly than when combined with rhBMP-2. The peculiar X-shape structure of the copolymers with a central ethylenediamine group may create an adequate environment for the ALP activity. Poloxamines are pointed out as a very promising material for syringeable in situ gelling systems with osteogenic performance, acting themselves as the active agent or as suitable BMP carriers. Although poloxamines are not biodegradable, it is expected that as the scaffold erodes and the copolymer reaches blood circulation, it could be rapidly excreted in the urine without toxic effects, as occurs for poloxamers. Nevertheless, in vivo studies are necessary to further clarify the clinical applicability of poloxamine gels. 


\section{Acknowledgements}

The work was financed by Xunta de Galicia (PGIDT07CSA002203PR and infrastructure grants DOG 04/06/97 and PGIDT 00PX120303PR), FEDER and MEC (SAF2008-01679). BASF Corporation (Amanda Hinckley and Mark Tapio) and CMM S.L. are thanked for providing poloxamine (Tetronic ${ }^{\circledR}$ ) and rhBMP-2 samples, respectively.

\section{References}

Al-Hanbali O, Onwuzo NM, Rutt KJ, Dadswell CM, Moghimi SM, Hunter AC (2007) Modification of the Stewart biphasic colorimetric assay for stable and accurate quantitatitive determination of Pluronic and Tetronic block copolymers for application in biological systems. Analytical Biochem. 361: 287-293.

Alvarez-Lorenzo C, Rey-Rico A, Brea J, Loza MI, Concheiro A, Sosnik A (2010a) Inhibition of P-glycoprotein pumps by PEO-PPO amphiphiles: Linear versus branched derivatives. Nanomedicine UK 5: 1371-1383.

Alvarez-Lorenzo C, Rey-Rico A, Sosnik A, Taboada P, Concheiro A (2010b) Poloxamine- based nanomaterials for drug delivery. Front Biosci E2: 424-440.

Alvarez-Lorenzo C, Gonzalez-Lopez J, FernandezTarrio M, Sandez-Macho I, Concheiro A (2007) Tetronic micellization, gelation and drug solubilization: influence of $\mathrm{pH}$ and ionic strength. Eur J Pharm Biopharm 66: 244 252.

Anderson BC, Pandit NK, Mallapragada SK (2001) Understanding drug release from poly(ethylene oxide)b-poly(propylene oxide)-b-poly(ethylene oxide) gels. J Control Release 70: 157-167.

Bessa PC, Casal M, Reis RL (2008a) Bone morphogenetic proteins in tissue engineering: the road from the laboratory to the clinic, part I (basic concepts). J Tissue Eng Regen Med 2: 1-13.

Bessa PC, Casal M, Reis RL (2008b) Bone morphogenetic proteins in tissue engineering: the road from laboratory to clinic, part II (BMP delivery). J Tissue Eng Regen Med 2: 81-96.

Bishop GB, Einhorn TA (2007) Current and future clinical applications of bone morphogenetic proteins in orthopaedic trauma surgery. Int Orthop 31: 221-226.

Bromberg LE, Ron ES (1998) Temperature-responsive gels and thermogelling polymers matrices for protein and peptide delivery. Adv Drug Del Revs 31: 197-221.

Chaibundit C, Ricardo NMPS, Costa FMLL, Yeates SG, Booth C (2007) Micellization and gelation of mixed copolymers P123 and F127 in aqueous solution. Langmuir 23: 9229-9236.

Cheng H, Jiang W, Phillips FM, Haydon RC, Peng Y, Zhou L, Luu HH, An N, Breyer B, Vanichakarn P, Szatkowski JP, Park JY, He TC (2003) Osteogenic activity of the fourteen types of human bone morphogenetic proteins (BMPs). J Bone Joint Surg Am 85: 1544-1552.

Chiappetta DA, Sosnik A (2007). Poly (ethylene oxide)poly (propylene oxide) block copolymer micelles as drug delivery agents: Improved hydrosolubility, stability and bioavailability of drugs. Eur J Pharm Biopharm 66: 303331.

Chiappetta DA, Alvarez-Lorenzo C, Rey-Rico A, Taboada P, Concheiro A, Sosnik A (2010) N-alkylation of poloxamines modulates micellar assembly and encapsulation and release of the antiretroviral efavirenz. Eur J Pharm Biopharm 76: 24-37.

Clokie CM, Urist MR (2000) Bone morphogenetic protein excipients: comparative observations on poloxamer. Plast Reconstr Surg 105: 628-637.

Cosmetic Ingredient Review (CIR) Expert Panel (2008) Safety assessment of poloxamers 101, 105, 108, 122, 123, $124,181,182,183,184,185,188,212,215,217,231$, $234,235,237,238,282,284,288,331,333,334,335$, 338, 401, 402, 403, and 407, poloxamer 105 benzoate, and poloxamer 182 dibenzoate as used in cosmetics. Int $\mathrm{J}$ Toxicol 27: 93-128.

Cowan CM, Aalami OO, Shi YY, Chou YF, Mari C, Thomas R, Quarto N, Nacamuli RP, Contag CH, Wu B, Longaker MT (2005) Bone morphogenetic protein 2 and retinoic acid accelerate in vivo bone formation, osteoclast recruitment, and bone turnover. Tissue Eng 11: 645-658.

Date T, Doiguchi Y, Nobuta M, Shindo H (2004) Bone morphogenetic protein-2 induces differentiation of multipotent $\mathrm{C} 3 \mathrm{H} 10 \mathrm{~T} 1 / 2$ cells into osteoblasts, chondrocytes, and adipocytes in vivo and in vitro. J Orthop Sci 9: 503-508.

Exner AA, Krupka TM, Scherrer K, Teets JM (2005) Enhancement of carboplatin toxicity by Pluronic block copolymers. J Control Release 106: 188-197.

Fisher JP, Jo S, Mikos AG, Reddi AH (2004) Thermoreversible hydrogel scaffolds for articular cartilage engineering. J Biomed Mater Res Part A 71A: 268-274.

Geiger M, Li RH, Friess W (2003) Collagen sponges for bone regeneration with rhBMP-2. Adv Drug Deliver Rev 55: 1613-1629.

Gonzalez-Lopez J, Alvarez-Lorenzo C, Taboada P, Sosnik A, Sandez-Macho I, Concheiro A (2008) Selfassociative behavior and drug-solubilizing ability of poloxamine (tetronic) block copolymers. Langmuir 24: 10688-10697

Gonzalez-Lopez J, Sandez-Macho I, Concheiro A, Alvarez-Lorenzo C (2010) Poloxamines and poloxamers as polymeric micellar carriers for simvastatin: interactions at the air-water interface and in bulk solution. J Phys Chem C 114: 1181-1189.

Harris MT, Butler DL, Boivin GP, Florer JB, Schantz EJ, Wenstrup RJ (2004) Mesenchymal stem cells used for rabbit tendon repair can form ectopic bone and express alkaline phosphatase activity in constructs. J Orthop Res 22: 998-1003.

He C, Kim SW, Lee DS (2008) In situ gelling stimulisensitive block copolymer hydrogels for drug delivery. J Control Release 127: 189-207.

Hedoux WJF, Paccou L, Guinet Y, Affouard F, Lerbret A, Descamps M (2009) Thermostabilization mechanism of bovine serum albumin by trehalose. J Phys Chem B 113: 6119-6126.

Helder MN, Wuisman PIJM, Zandieh Doulabi B (2007) Method for induction of differentiation of stem and progenitor cells. Patent WO/2007/108689. 
Helm GA, Sheehan JM, Sheehan JP, Jane JA Jr, diPierro CG, Simmons NE, Gillies GT, Kallmes DF, Sweeney TM (1997) Utilization of type I collagen gel, demineralized bone matrix, and bone morphogenetic protein-2 to enhance autologous bone lumbar spinal fusion. J Neurourg 86: 93 100 .

Hing KA (2004) Bone repair in the twenty-first century: biology, chemistry or engineering? Phil. Trans. R. Soc. Lond. A 362: 2821-2850.

Hsieh CY, Hsieh HJ, Liu HC, Wang DM, Hou LT (2006) Fabrication and release behavior of a novel freeze-gelled chitosan/g-PGA scaffold as a carrier for rhBMP-2. Dent Mater 22: 622-629.

Hutmacher DW, Sugunan SLC (2004) Bone repair and adult stem cells, in: Stem Cells, from Bench to Bedside, Bongso A, Lee EH (Eds), World Scientific Publishing Co., Singapore, p. 451.

Issa JPM, do Nascimento C, Iyomasa MM, Siessere S, Regalo SCH, Defino HLA, Sebald W (2008) Bone healing process in critical-sized defects by rhBMP-2 using poloxamer gel and collagen sponge as carriers. Micron 39: 17-24.

Itosaka H, Kuroda S, Shichinohe H, Yasuda H, Yano S, Kamei S, Kawamura R, Hida K, Iwasaki Y (2009) Fibrin matrix provides a suitable scaffold for bone marrow stromal cells transplanted into injured spinal cord: A novel material for CNS tissue engineering. Neuropathology 29 248-257.

Jaiswal N, Haynesworth SE, Caplan AI, Bruder SP (1997) Osteogenic differentiation of purified, cultureexpanded human mesenchymal stem cells in vitro. J Cell Biochem 64: 295-312.

Jeon O, Song SJ, Kang S, Putnam AJ, Kim B (2007) Enhancement of ectopic bone formation by bone morphogenetic protein-2 released from a heparinconjugated poly(L-lactic-co-glycolic acid) scaffold. Biomaterials 28: 2763-2771.

Jeon JH, Puleo DA (2008) Alternating release of different bioactive molecules from a complexation polymer system. Biomaterials 29: 3591-3598

Ji XH, Chen D, Xu C, Harris SE, Mundy GR, Yoneda T (2000) Patterns of gene expression associated with BMP-2-induced osteoblast and adipocyte differentiation of mesenchymal progenitor cell 3T3-F442A. J Bone Miner Metab 18: 132-139.

Jones DS, Muldoon BCO, Woolfson AD, Andrews GP, Mccoy CP, Sanderson FD (2010) Moisture-activated rheological structuring of nonaqueous poloxaminepoly(acrylic acid) systems designed as novel biomedical implants. J Pharm Sci 99: 1838-1854.

Kabanov AV, Alakhov VY (2002) Pluronic(R) block copolymers in drug delivery: From micellar nanocontainers to biological response modifiers. Crit Rev Ther Drug 19: 1-72.

Kato S, Kawabata N, Suzuki N, Ohmura M, Takagi M (2009) Bone morphogenetic protein-2 induces the differentiation of a mesenchymal progenitor cell line, ROB-C26, into mature osteoblasts and adipocytes. Life Sci 84: 302-310.
Kim HD, Valentini RF (2002) Retention and activity of BMP-2 in hyaluronic acid-based scaffolds in vitro. $\mathrm{J}$ Biomed Mater Res 59: 573-584.

Kim HW, Lee HH, Chun GS (2008) Bioactivity and osteoblast responses of novel biomedical nanocomposites of bioactive glass nanofiber filled poly(lactic acid). J Biomed Mater Res 85A: 651-663.

Krupka TM, Dremann D, Exner AA (2009) Time and dose dependence of pluronic bioactivity in hyperthermiainduced tumor cell death. Exp Biol Med 234: 95-104.

Li RH, Wozney JM (2001) Delivering on the promise of bone morphogenetic proteins. Trends Biotechnol 19: 255-265.

Li X, Yao J, Wu L, Jing W, Tang W, Lin Y, Tian W, Liu L (2009) Osteogenic induction of adipose-derived stromal cells: not a requirement for bone formation in vivo. Artif Organs 34: 46-54.

Luginbuehl V, Meinel L, Merkle HP, Gander B (2004) Localized delivery of growth factors for bone repair. Eur J Pharm Biopharm 58: 197-208.

Lutolf MP, Lauer-Fields JL, Schmoekel HG, Metters AT, Weber FE, Fields GB, Hubbell JA (2003a) Synthetic matrix metalloproteinase-sensitive hydrogels for the conduction of tissue regeneration: Engineering cellinvasion characteristics. Proc Natl Acad Sci USA 100: 5413-5418.

Lutolf MP, Weber FE, Schmoekel HG, Schense JC, Kohler T, Mueller R, Hubbell JA (2003b) Repair of bone defects using synthetic mimetics of collagenous extracellular matrices. Nat Biotechnol 21: 513-518.

McKay WF, Peckham SM, Badura JM (2007) A comprehensive clinical review of recombinant human bone morphogenetic protein-2 (INFUSE Bone Graft). Int Orthop 31: 729-734.

Moghimi SM, Hunter AC, Murray JC (2001) Longcirculating and target-specific nanoparticles: theory to practice. Pharmacol Rev 53: 283-318.

Moses MA, Sudhalter J, Langer R (1992) Isolation and characterization of an inhibitor of neovascularization from scapular chondrocytes. J Cell Biol 119: 475-482.

Niemeyer P, Kasten P, Simank HG, Fellenberg J, Seckinger A, Kreuz PC, Mehlhorn A, Südkamp NP, Krause U (2006) Transplantation of mesenchymal stromal cells on mineralized collagen leads to ectopic matrix synthesis in vivo independently from prior in vitro differentiation. Cytotherapy 8: 354-366.

Park JC, Park BJ, Lee DH, Suh H, Kim D-G, Kwon O-H (2002) Evaluation of the citotoxicty of polyetherurethane (PU) film containing zinc diethyldithiocarbamate (ZDEC) on various cell lines. Yonsei Med J 43: 518-526.

Pelin IM, Maeir SS, Chitanu GC, Bulacovschi (2009) Preparation and characterization of a hydroxyapatitecollagen composite as component for injectable bone substitute. Mat Sci Eng C-Mater 29: 2188-2194.

Poynton AR, Lane JM (2002) Safety profile for the clinical use of bone morphogenetic proteins in the spine. Spine 27: 40-48.

Pratt AB, Weber FE, Schmoekel HG, Mueller R, Hubbell JA (2004) Synthetic extracellular matrixes for in situ tissue engineering. Biotechnol Bioeng 86: 27-36. 
Puppi D, Chiellini F, Piras A M, Chiellini E (2010) Polymeric materials for bone and cartilage repair. Prog Polym Sci 35: 403-440.

Rai B, Teoh SH, Hutmacher DW, Cao T, Ho KH (2005) Novel PCL-based honeycomb scaffolds as drug delivery systems for rhBMP-2. Biomaterials 26: 3739-3748.

Reddi AH (2005) BMPs: from bone morphogenetic proteins to body morphogenetic proteins. Cytokine Growth F R 16: 249-250.

Schoichet MS (2010) Polymer scaffolds for biomedical applications. Macromolecules 43: 581-591.

Seeherman HJ, Bouxsein M, Kim H, Li R, Li XJ, Aiolova M, Wozney JM (2004) Recombinant human bone morphogenetic protein-2 delivered in an injectable calcium phosphate paste accelerates osteotomy-site healing in a nonhuman primate model. J Bone Joint Surg Am 86: 1961-1972.

Seeherman H, Wozney JM (2005) Delivery of bone morphogenetic proteins for orthopedic tissue regeneration. Citokyne Growth F R 16: 329-345.

Shen H, Hu X, Yang F, Bei J, Wang S (2009) The bioactivity of rhBMP-2 immobilized poly(lactide-coglycolide) scaffolds. Biomaterials 30: 3150-3157.

Sopyana I, Melb M, Ramesh S, Khalid KD (2007) Porous hydroxyapatite for artificial bone applications. Sci Technol Adv Mater 8: 116-123.

Sosnik A, Leung BM, Sefton MV (2008) Lactoylpoloxamine/collagen matrix for cell-containing tissue engineering modules. J Biomed Mat Res A 86A: 339-353.

Takahashi Y, Yamamoto M, Tabata Y (2005) Enhanced osteoinduction by controlled release of bone morphogenetic protein-2 from biodegradable sponge composed of gelatin and $\beta$-tricalcium phosphate. Biomaterials 26: 4856-4865.

Tjabringa GS, Zandieh-Doulabi B, Helder MN, Knippenberg M, Wuisman PIJM, Klein-Nulend J (2008) The polymine spermine regulates osteogenic differentiation in adipose stem cells. J Cel Mol Med 12: 1710-1717.

Trentz OA, Arikketh D, Sentilnathan V, Hemmi S, Handschin AE, de Rosario B, Mohandas P, Mohandas PVA (2010) Surface proteins and osteoblast markers: characterization of human adipose tissue-derived osteogenic cells. Eur J Trauma Emerg Surg 36: 457-463.

Uludag H, D'Augusta D, Plamer R, Timony G; Wozney J (1999) Characterization of rhBMP-2 pharmacokinetics implanted with biomaterial carriers in the rat ectopic model. J. Biomed. Mater Res 46: 193-202.

Urist MR (1965) Bone: formation by autoinduction. Science 150: 893-898.

Vashi AV, Keramidaris E, Abberton KM, Morrison WA, Wilson JL, O'Connor AJ, Cooper-White JJ, Thompson EW (2008) Adipose differentiation of bone marrow-derived mesenchymal stem cells using Pluronic F-127 hydrogel in vitro. Biomaterials 29: 573-579.

Wahlstroem O, Linder C, Anders K, Per M (2007) Variation of $\mathrm{pH}$ in lysed platelet concentrates influence proliferation and alkaline phosphatase activity in human osteoblast-like cells. Platelets 18: 113-118.

Wang EA, Rosen V, D’Alessandro JS, Bauduy M, Cordes P, Harada T, Israel DI, Hewick RM, Kerns M, LaPan P (1990) Recombinant human bone morphogenetic protein induces bone formation. Proc Natl Acad Sci USA 87: 2220-2224.

Westerhuis RJ, van Bezooijen RL, Kloen P (2005) Use of bone morphogenetic proteins in traumatology. Injury, Int J Care Injured 36: 1405-1412.

White AP, Vaccaro AR, Hall JA, Whang PG, Friel BC, McKee MD (2007) Clinical applications of BMP-7/OP-1 in fractures, nonunions and spinal fusion. Int Orthop 31: 735-741.

Winn SR, Uludag H, Hollinger JO (1999) Carrier systems for bone morphogenetic proteins. Clin Orthop 357: 95-106.

Woerle G, Siekmann B, Koch MHJ, Bunje H (2006) Transformation of vesicular into cubic nanoparticles by autoclaving of aqueous monoolein/poloxamer dispersions. Eur J Pharm Sci 27: 44-53.

Xian W (2009) A laboratory course in biomaterials. CRC Press, Boca Raton, p. 115.

Yang SH, Hsu CK, Wang KC, Hou SM, Lin FH (2005) Tricalcium phosphate and glutaraldehyde crosslinked gelatin incorporating bone morphogenetic protein - a viable scaffold for bone tissue engineering. J Biomed Mater Res B Appl Biomater 74: 468-475.

Yin Z, Chen X, Chen JL, Ouyang HW (2010) Stem cells for tendon tissue engineering and regeneration. Expert Opin Biol Ther 10: 1-12.

Yu L, Ding J (2008) Injectable hydrogels as unique biomedical materials. Chem Soc Rev 37: 1473-1481.

Zuk PA, Zhu M, Ashjian P, Ugarte DA de, Huang JI, Mizuno H, Alfonso ZC, Fraser JK, Benhaim P, Hedrick MH (2002) Human adipose tissue is a source of multipotent stem cells. Mol Cell Biol 13: 4279-4295.

\section{Discussion with Reviewer}

Reviewer II: In the release studies the gel was formed at $37{ }^{\circ} \mathrm{C}$ in test tubes and the phosphate buffer solution was added over the mass formed. Please include more details on the geometry of the gel samples and on the surface available between the gel samples and the liquid medium, as these aspects can influence the release profile.

Authors: Since the poloxamine solutions underwent the sol to gel transition inside the test tubes, the gels adopted a cylindrical shape having a diameter equals to the inner diameter of the test tube. The inner diameters of the test tubes and the surface area of the gel in contact with the release medium were $13.5 \mathrm{~mm}$ and $143.1 \mathrm{~mm}^{2}$ respectively.

Reviewer II: The authors present rheological data performed on well established systems. How they can be compared with other rheological results previously reported in the literature?

Authors: At $37^{\circ} \mathrm{C}$, Tetronic 908, 1107, 1301 and 1307 systems behave as gels with storage modulus ranging between $10^{3}$ and $10^{5} \mathrm{~Pa}$. These values, which are similar to those we obtained for Pluronic F127, are in the range of those previously reported for other in situ gelling systems and syringeable depots for drug delivery (Chaibundit et 
al., 2007; Jones et al., 2009, text references). Furthermore, the storage modulus values are in the range of those found for preformed bone scaffolds such as hydroxyapatiteatelocollagen composites (Pelin et al., 2009, text reference). Reviewer II: The release profile of both BSA and BMP-2 are given in cumulative (total) mass released. What is the correspondence of such values with respect to the total amount of proteins initially present in the gel samples? Could the authors indicate for both BMP-2 and BSA what $\%$ was released after $1 \mathrm{~d}$ and at the last time point? Could the authors comment on this release profiles? Are the release profiles adequate in respect of the application? How do these systems compare to the ones available in the literature?

Authors: 100\% BSA and BMP-2 released correspond to 10 and $0.06 \mathrm{mg}$, respectively. Regarding BSA, Tetronic 908 and 1107 formulations released $50-60 \%$ at $24 \mathrm{~h}$ and nearly $90 \%$ at day 7 , while Tetronic 1301 and 1307 formulations released $30-35 \%$ at $24 \mathrm{~h}$ and ca. $75 \%$ at day 7 . Regarding BMP-2, Tetronic 908, 1107 and 1307 gels released 58, 41 and $32 \%$ at $24 \mathrm{~h}$ and 75,55 and $82 \%$ at day 7 , respectively. Although a pharmacokinetic profile predictive of success has not been identified yet, previous studies have shown that efficient scaffolds should combine a reasonably high initial release with a sustained delivery behavior later on (Uludag et al., 1999, text reference). Therefore, the poloxamine-based formulations seem to be suitable for the delivery of rhBMP-2.

Reviewer II: The authors should comment on the applicability of such materials as matrices for the delivery of growth factors taking into account that they are not biodegradable.

Authors: It has been previously reported that poloxamers injected intravenously are rapidly excreted in the urine, with minor accumulation in lung, liver, brain, and kidney tissue, and no risk of reproductive and/or developmental toxicity has been found (Cosmetic Ingredient Review (CIR) Expert Panel, 2008, text reference). Since poloxamines possess a polyoxyethlyene-polyoxypropylene block composition similar to that of poloxamers, nonbiodegradable poloxamine matrices are expected to erode releasing the copolymer to the blood circulation, from which the poloxamines could be rapidly cleared through kidney filtration. 